\title{
FROM SHAME TO GAME IN ONE HUNDRED YEARS: AN ECONOMIC MODEL OF THE RISE IN PREMARITAL SEX AND ITS DE-STIGMATIZATION
}

\author{
Jesús Fernández-Villaverde \\ University of Pennsylvania
}

\author{
Nezih Guner \\ ICREA-MOVE, Universitat Autonoma \\ de Barcelona, and Barcelona GSE
}

\author{
Jeremy Greenwood \\ University of Pennsylvania
}

\begin{abstract}
Societies socialize children about sex. This is done in the presence of peer-group effects, which may encourage undesirable behavior. Parents want the best for their children. Still, they weigh the marginal gains from socializing their children against its costs. Churches and states may stigmatize sex, both because of a concern about the welfare of their flocks and the need to control the cost of charity associated with out-of-wedlock births. Modern contraceptives have profoundly affected the calculus for instilling sexual mores. As contraception improves there is less need for parents, churches, and states to inculcate sexual mores. Technology affects culture. (JEL: D58, J13, O15, N30)
\end{abstract}

\section{Introduction}

Shame is a disease of the last age; this seemeth to be cured of it.

Marquis of Halifax (1633-1695)

The last one hundred years have witnessed a revolution in sexual behavior. In 1900 , only $6 \%$ of US women had engaged in premarital sex by age 19 ; see the right panel of Figure 1. (All data sources are discussed in the Data Appendix.) The number is now $75 \%$. Public acceptance of this practice reacted with delay. Only $15 \%$ of women

\footnotetext{
The editor in charge of this paper was Fabrizio Zilibotti.

Acknowledgments: Helpful comments from referees are gratefully acknowledged. Thanks are extended to Effrosyni (Efi) Adamopoulou, Sally Burke, Georgi Kocharkov, Junwen (Caroline) Liu, and, especially, Ezgi Kaya for help with the paper. Nezih Guner acknowledges support from the European Research Council (ERC Grant 263600). This research uses data from Add Health, a program project designed by J. Richard Udry, Peter S. Bearman, and Kathleen Mullan Harris. Special acknowledgment is due to Ronald R. Rindfuss and Barbara Entwisle for assistance in the original design.

E-mails: jesusfv@econ.upenn.edu (Fernández-Villaverde); nezih.guner@movebarcelona.eu (Guner)
} 

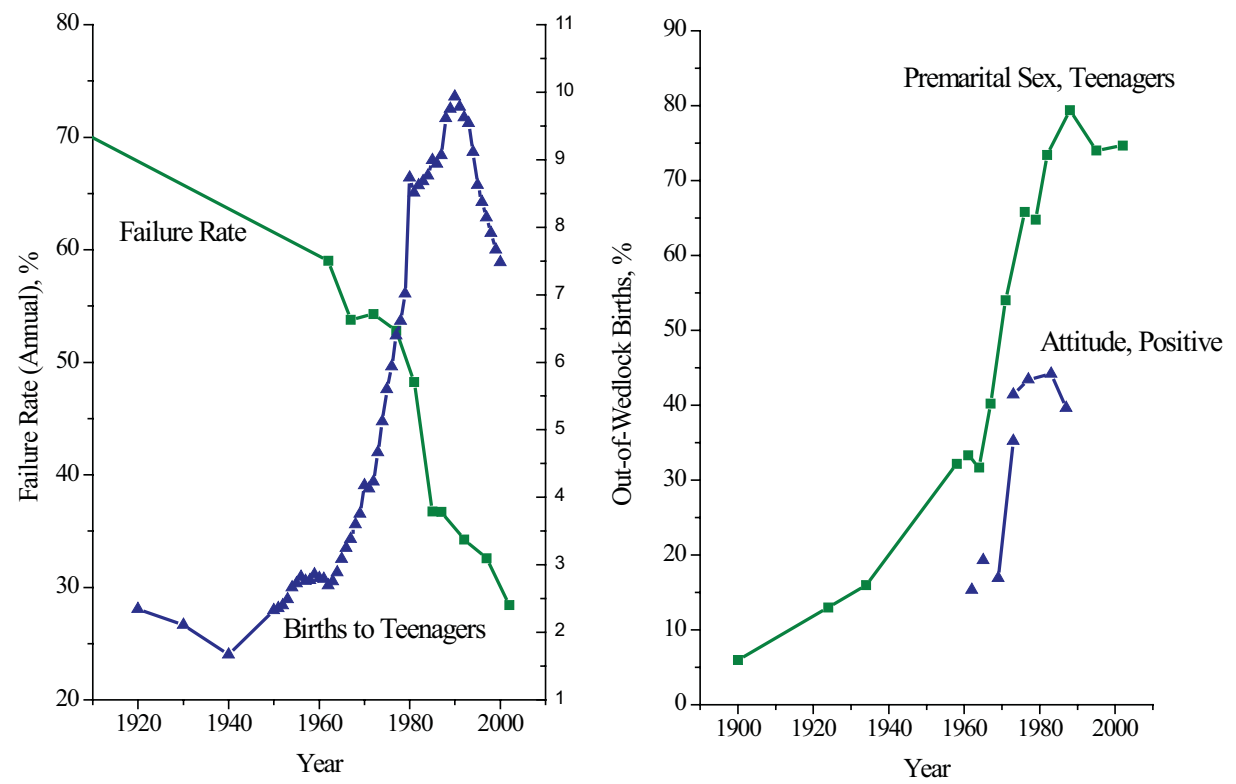

FIGURE 1. The right panel shows premarital sexual experience by teenagers and attitudes by all women. The left panel plots the effectiveness of contraception and out-of-wedlock births to teenage girls (as a fraction of all unmarried teenagers). Data sources for all figures are discussed in the Data Appendix.

in 1968 had a permissive attitude toward premarital sex. ${ }^{1}$ At the time, though, about $40 \%$ of 19 -year-old females had experienced it. The number with a permissive attitude had jumped to $45 \%$ by 1983 , a time when $73 \%$ of 19 -year-old women had experienced premarital sex. Thus, societal attitudes lagged practice. Beyond the evolution and acceptance of sexual behavior over time, there are relevant cross-sectional differences across women. In the United States, the odds of a girl having premarital sex decline with family income. So, for instance, in the bottom decile, $70 \%$ of girls between the ages of 15 and 19 have experienced it, versus $47 \%$ in the top decile. Similarly, 68\% of adolescent girls whose family income lies in the upper quartile would feel "very upset" if they got pregnant, versus $46 \%$ of those whose family income is in the lower quartile.

What caused this sexual revolution? The obvious hypothesis is technological innovation in contraception. Figure 1, left panel, shows how the odds of becoming pregnant (the failure rate) from premarital sex have declined rapidly, both due to technological improvement in contraception and the increased use of contraception by teenagers due to the dissemination of knowledge by the birth control movement. This has reduced the riskiness of premarital sex. It has also led to the paradoxical situation

1. The number with a permissive attitude is defined as the fraction of women who indicated that a sexual relationship before marriage was not wrong (or was wrong only sometimes) in national opinion surveys such as Gallup or the General Social Survey (GSS). 
in which, despite the fact that the efficacy of contraception has increased, the number of out-of-wedlock births has risen.

An overlapping generations model is presented here that can account for the rise in premarital sex and the decline in the shame and stigma associated with it. It is also consistent with the cross-sectional observations about sex and attitudes toward it. The analysis has two main ingredients. First, young women act in their own best interest when deciding to engage in premarital sex. They weigh the benefits from the joy of sex against its expected cost, the possibility of having an out-of-wedlock birth. In the analysis, an out-of-wedlock birth hurts a woman by both reducing her productivity in the labor market (a shorthand for missed educational and job opportunities) and hurting her prospects in the marriage market. As the failure rate for contraception drops, the cost of engaging in premarital sex will fall. This leads to more teenage girls engaging in it.

Second, young women feel shame associated with an out-of-wedlock birth. The level of shame is determined by the socialization efforts of parents. Parents socialize by molding the preferences of their daughters. Socializing a child is costly in terms of effort for parents. Parents do this because they care about the well-being of their daughters when the latter grow up. When picking the level of socialization, parents take into account that their daughter will act in her own best interest. The model also includes a role for peer-group effects. In particular, a young woman feels less shame from having an out-of-wedlock birth when her friends and acquaintances are engaging in premarital sex. Peer-group effects operate to increase the equilibrium amount of premarital sex. As contraception improves, the need for parental socialization diminishes. Additionally, girls will feel less guilt about engaging in premarital sex because more of their friends are. The overall drop in shame associated with premarital sex can be viewed as cultural change.

A steady state for the model is calibrated to match stylized facts for today's US economy. This is done to show that the framework can replicate some features of modern times and to discipline the analysis before computing the transitional dynamics for the model. The stylized facts are: (i) the cross-sectional relationship between a girl's education and the likelihood that she will engage in premarital sex; (ii) the amount of time that a mother spends socializing her daughter as a function of the former's educational background; (iii) the degree of assortative mating in the United States conditioned upon the presence or not of an out-of-wedlock birth; and (iv) the effects of peers on the likelihood that a girl will enter into a sexual relationship. Transitional dynamics are computed for the situation where society faces a known time path of technological progress in its contraceptive technology. It is demonstrated that the model can replicate the observed rise in premarital sex and out-of-wedlock births.

Institutions such as the church and state also care about the level of out-of-wedlock births in society. Typically they have provided unwed mothers with charity. The model is extended to capture such concern by societal institutions. In particular, a Ramseystyle problem is considered where the church-cum-state tries to influence parental attitudes about illegitimacy in order to minimize the number of out-of-wedlock births net of the cost of swaying attitudes. In the extension, a parent whose child has an 
out-of-wedlock birth will feel some sort of stigma. This encourages parents to provide a moral education for their children, say by taking them to church. When shaping parental attitudes, the church-cum-state takes into account the influence that it has on peer-group behavior. This is something, society's mores so to speak, that parents must take as exogenous when deciding how to socialize their daughters. Group behavior is something that social institutions may sway, however. Again, as contraception becomes more effective there is less need to engage in such stigmatization. Once again, technology affects culture.

Before proceeding to an exploration of the historical evidence, a brief literature review will be presented. First, Greenwood and Guner (2010) also study the impact that technological advance in contraception has had on social behavior and interaction. They build an equilibrium search model where youths make decisions about which social groups (either abstinent or promiscuous ones) to circulate within. The group a child mixes with will depend both on the state of contraceptive technology and on what others are doing. Greenwood and Guner define social change simply as shifts in the relative sizes of these social groups, which reflect the aggregation of decentralized decision making at the individual level. There is no consideration of the role that either parents or social institutions may play in shaping youths' attitudes toward premarital sex.

Second, the modern analysis of how a child's preferences can be molded by parental investments starts with Becker (1993), who was undoubtedly influenced by the work of Coleman (1990). He explored how parents may predispose childrens' preferences toward providing them with old-age support. Becker and Mulligan (1997) focus on the manipulation of the child's rate of time preference. This idea is extended in Doepke and Zilibotti's (2008) work on the decline of the aristocracy that accompanied the British Industrial Revolution. They argue that parents, who thought that their children might enter the class of skilled workers, instilled in their offspring a patience that allowed their children to sacrifice today in order to acquire the human capital necessary so that they would earn more tomorrow. Tabellini (2008) studies how social norms for cooperation evolve over time as parents transmit values to their children. As in the current paper, parents are not fully altruistic. They make an investment decision that influences the values that are transmitted to their offspring. Changes in the economic environment and parental decisions reinforce each other. Bisin and Verdier (2001) approach the problem of preference transmission from a different perspective: parents want their children to behave like them. Hauk and Saez-Marti (2002) use a variant of the Bisin and Verdier (2001) framework to study the cultural transmission of corruption. In their framework, an honest person suffers from behaving dishonestly. Honest parents educate their children, at a cost, with the hope that the latter will inherit (in a probabilistic manner) this notion of guilt associated with dishonest behavior. This is similar to the concept of shame analyzed here.

Third, there is a large empirical literature relating culture and economic behavior that is too wide to survey here. Guiso, Sapienza, and Zingales (2006) provide a nice summary of many of the issues studied by economists over the last few years. Of particular interest is the evidence regarding the effect of "ethnic capital" as documented 


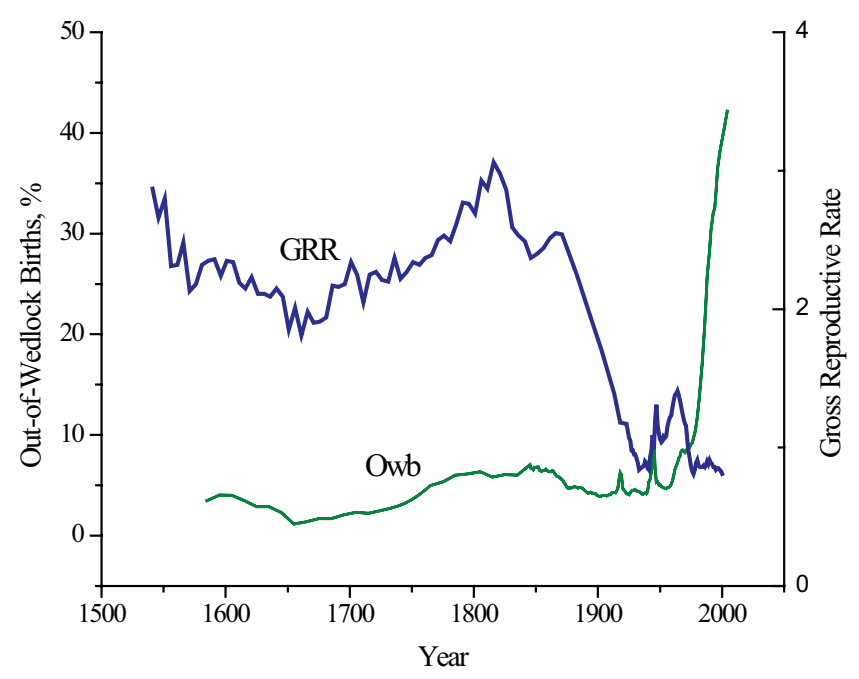

FIGURE 2. The percentage of all births that are out-of-wedlock (or the illegitimacy ratio) from 1580-2004 and the gross reproductive rate for 1540-2000, for both England and Wales.

by Fernández and Fogli (2009) and Giuliano (2007). The current analysis can be used to interpret this evidence as the result of the persistence in parents' decisions induced by the role that socialization plays as a state variable - that is, the action of a youth today is influenced by the socialization she or he received from her or his parents, which in turn is affected by the socialization they experienced from their parents.

\section{Historical Discussion}

Every lewd woman which shall have any bastard which may be chargeable to the parish, the justices of the peace shall commit such woman to the house of correction, to be punished and set on work during the term of one whole year.

Statute of 7 James, cap 4 (1610)

Widespread participation in premarital sex is a recent phenomenon in Western societies. In yesteryear the most probable scenario is that only a small fraction of women engaged in premarital sex, especially relative to modern times. There have been places and times in the past, however, where significant, but still relatively moderate, fractions of the female population may have engaged in it. The first port of call for those interested in demographic history is England, for which reasonably accurate and detailed data have been assembled. Figure 2 plots out-of-wedlock births as a percentage of all births (the illegitimacy ratio) for England and Wales from 1580 to 2004. It is interesting to note that the recent rise in out-of-wedlock births occurred at a time when the gross reproductive rate (GRR) was declining. The small number of out-of-wedlock births is also surprising in light of the fact that for much of the period women tended to marry late (around 26 years of age in the 17th century), with a significant fraction never 
marrying; see Voigtländer and Voth (2013) for a discussion of the European marriage pattern.

Engaging in premarital sex (without a betrothal) was, until recently, a risky venture. First, it was illegal and viewed as morally reprehensible. Second, an out-of-wedlock birth placed a woman in a perilous economic state. Some historical examples of how premarital sex was stigmatized will now be presented. In 1601, the Lancashire Quarter Sessions ordered an unmarried father and mother of a child to be publicly whipped. ${ }^{2}$ They then had to sit in the stocks naked from the waist up. A placard on their heads read "These persons are punished for fornication." In early America, a New Haven court in 1648 fined a couple for having sex out of marriage. The magistrate ordered that the couple "be brought forth to the place of correction that they may be shamed." He said that premarital sex was "a sin which lays them open to shame and punishment in this court. It is that which the Holy Ghost brands with the name of folly, it is wherein men show their brutishness, therefore as a whip is for the horse and asse, so a rod is for the fool's back." These were not isolated cases. The prosecution of single men or women for "fornication" or of married couples who had a child before wedlock accounted for 53\% of all criminal cases in Essex County, Massachusetts, between 1700 and 1785 . Likewise, $69 \%$ of all criminal cases in New Haven between 1710 and 1750 were for premarital sex.

It is also telling that in colonial America, abortion was punished when it was intended to cover adultery or fornication; however, it was overlooked when it was used as a device to control fertility within a marriage. In Pennsylvania, the law was taken one step further. If a bastard child was found dead, the mother was presumed to be guilty unless she could prove otherwise, overriding the general English legal principle of presumption of innocence. This change in the legal principle was particularly harsh, as the punishment for the crime could be hanging.

The economic consequences for an unwed mother and her child could be dire. Churches, courts, and parents tried to make the father and mother of an out-ofwedlock child marry. The next best option was to ensure that the father paid child support. Sometimes neither of these two options worked. The outlook for the mother and child could then be bleak. Note that the statute cited at the beginning of this section seemed only to apply to women who needed support. So, the widespread rule of Western societies was to shame and stigmatize premarital sex in order to limit out-of-wedlock births-19th-century France is an exception that proves the rule. It was an anomaly compared with other Western European countries and provides an interesting illustration of how the environment can affect social behavior. ${ }^{3}$ The French Civil Code of 1804 prohibited questioning by the authorities about a child's paternity. As a consequence, men could evade responsibility for bringing up their

2. This case is taken from the classic book by Stone (1977, p. 637). The discussion on premarital sex in early America largely derives from Godbeer (2002). The law in colonial Pennsylvania regarding bastards is mentioned in Klepp (1994, p. 74). Some additional historical material is included in the Online Appendix, Section A.

3. The material on France is drawn exclusively from Fuchs (1992). 
illegitimate offspring. Roughly at the same time, all French hospitals were instructed to accept abandoned children. These laws may have drastically changed the cost and benefit calculations of engaging in premarital sex and encouraged illegitimacy and abandonment on a grand scale. In 1816 about $40 \%$ of births in Paris were out of wedlock, and $55 \%$ of these children were abandoned. In 1820 a staggering $78 \%$ of these died. (Many of these out-of-wedlock births were undoubtedly from young women who lived outside of Paris and who moved to the anonymity of the capital after getting pregnant.) Why would an unwed mother abandon her child?

The decision to abandon a child was most likely dictated by economic circumstances. A woman was paid about half that of a man in a similar job. Her earnings barely covered her subsistence. In the 1860s, a working woman could earn somewhere between Fr250 and Fr600 a year taking into account seasonal unemployment. It cost approximately Fr300 a year for rent, clothing, laundry, heat, and light. Even at the maximum salary this did not leave much for food-less than a franc a day-let alone the costs of clothing and wet nursing a baby (the latter is estimated at $\operatorname{Fr} 300$ a year). A working woman could certainly not afford to raise a child alone. Furthermore, there is evidence, especially for the early part of the century, that child abandonment was correlated with the price of bread.

Next it will be shown that, even today, shame influences the sexual behavior of teenagers. This force may be mitigated by the presence of peer-group effects. Specifically, teens may feel less shame about engaging in premarital sexual activity when a significant number of their peers are sexually active. This will be investigated too. Beyond providing more supportive evidence for the developed model, the next section will play a disciplining role for the calibration undertaken in Section 8.

\section{Evidence on Shame and Peer-Group Effects in the United States, 1994-1996}

Does shame have an impact on teenage sexual behavior in modern times, when contraception is readily available? Data from the National Longitudinal Study of Adolescent Health (Add Health) will be used to address this question. Add Health is a representative sample of US adolescents who were in grades 7 to 12 at 134 junior and senior high schools during the 1994-1995 school year. The respondents have been followed in four waves, although for the current purpose only the first two (1994 and 1996, a panel of about 15,000 students) are needed. Add Health is particularly well suited for the study of social interactions because it contains detailed information about sexual behavior, sexual knowledge, shame from premarital sex or pregnancy, religiosity, parental background, school characteristics, and so forth. Furthermore, there are observations for many students from the same school and respondents are asked to identify their friends from the sample. Thus, peer groups can be constructed from either students who attend the same school or from groups of friends.

Peer-group effects may play an important role in explaining premarital sex. Teenagers may be more likely to engage in this activity if their friends or classmates 
do so. Thus, the transition from the limited amount of teenage sexual activity in the past to the widespread participation today may have been influenced by such effects.

So, what factors in the data affect the chances that a teenage girl will engage in premarital sex? To investigate this, think about all girls in Wave I who have not yet experienced premarital sex. Consider a logistic regression of the form

$$
\operatorname{Pr}\left(y=1 \mid \boldsymbol{x}, \bar{y}_{-i,-1}\right)=L\left(\alpha+\beta \boldsymbol{x}+\gamma \bar{y}_{-i,-1}\right),
$$

where the independent variable $y$ takes the value of 1 if a teenage girl starts having sex between Waves I and II and 0 otherwise, $\boldsymbol{x}$ is a vector of explanatory variables (including a measure of shame discussed in what follows), $\bar{y}_{-i,-1}$ is the fraction of teenage girls among the respondent's peers who have already had premarital sex in Wave I, and $L$ is the (cumulative) logistic distribution function. The vector $\boldsymbol{x}$ includes variables related to shame, religion, family background, and so forth, that are reported in Add Health.

The previous logistic regression and the panel structure of the data set mitigate the "reflection problem" prevalent in cross-sectional samples: group behavior affects individual behavior but the group by definition is the sum of the individuals. In particular, the analysis focuses on those girls who made the transition from never having premarital sex in Wave I to having had it in Wave II. Therefore, this subset of girls could not have influenced those who had sex in Wave I, which is the peer group. Thus, $\bar{y}_{-i,-1}$ can be taken as exogenous in the regression. ${ }^{4}$

\subsection{The Shame Variable}

Add Health contains several different variables both on the shame from sex and how religious a teenager is. Since these variables are correlated, it is not desirable to use them all. Instead, factor analysis is employed to consolidate the variables into a single one called shame. The basic idea is that there is a common factor, shame, that affects a respondent's answers. In the factor analysis, eleven variables are used relating to the perceived shame a teenage girl would feel from her mother or family regarding premarital sex, the personal shame/concern the teenager would have about sex, her shame/concern about a pregnancy, and her religiosity. These eleven variables are then statistically aggregated into a common single shame variable via factor analysis. This single factor explains about $50 \%$ of the variation in these eleven variables; see Online Appendix, Section B, for a brief discussion of factor analysis and a complete list of the variables used. A higher value for this aggregated variable indicates less shame.

\subsection{Results}

Table 1 shows the coefficients from different logistic regressions. In all regressions the dependent variable reports whether the respondent started having sex between Wave I

4. Clark and Loheac (2007) use a similar approach to study teenage consumption of alcohol, marijuana and tobacco. 
TABLE 1. Peer-group effects and shame.

\begin{tabular}{lccrrrr}
\hline & I & II & III & IV & V & \multicolumn{1}{c}{ VI } \\
\hline School average & $1.741^{* *}$ & $1.592^{* * *}$ & $1.288^{* *}$ & $1.663^{* * *}$ & $1.780^{* *}$ & \multicolumn{1}{c}{$1.722^{*}$} \\
Shame & $0.641^{* * *}$ & $0.645^{* * *}$ & $0.663^{* * *}$ & $0.617^{* * * *}$ & $0.581^{* * *}$ & \multicolumn{1}{c}{$0.606^{* * * *}$} \\
Parental income & & & $-0.007^{* * *}$ & $-0.008^{* * *}$ & $-0.007^{* *}$ & $-0.007^{* *}$ \\
Romantic relationship & & & & $1.788^{* * *}$ & $1.677^{* * *}$ & $1.650^{* * * *}$ \\
Grades & & & & & $0.379^{* *}$ & $0.351^{* *}$ \\
Physical development & & & & & & $0.582^{* * *}$ \\
Control for race & No & Yes & Yes & Yes & Yes & Yes \\
Control for age & No & Yes & Yes & Yes & Yes & Yes \\
No. of obs. & 1,986 & 1,985 & 1,505 & 1,505 & 1,142 & 1,142 \\
\hline
\end{tabular}

***Significant at $1 \%$; **ignificant at $5 \%$; *significant at $10 \%$.

and Wave II. The table starts with a simple specification where the only explanatory variables are shame and the fraction of teenagers who have already had sex in the respondent's school in Wave I (to capture the peer-group effects). Both the peer-group and shame variables have significant effects on teenage initiation into premarital sex (the normalization of the shame factor implies that higher values of the variable are associated with weaker feelings of shame). Next, controls are added for race and age. Controls are then included for observations such as parental income in Wave I, whether or not the respondent has a romantic relationship in Wave II, her grades (an average of her math, English, science and social sciences scores, with a lower number indicating a higher average), and whether the teenager believes that she looks older than her peers.

The main lesson from Table 1 is that the effect of peer groups and shame is very robust across these different specifications. In all of the regressions, the standard errors are adjusted using Add Health's clustered sampling design. Since the shame variable is a generated regressor, it is subject to statistical variation and this should be taken into account in the standard error calculations. Following Cameron and Trivedi (2005), a simple approach to fix this problem is to obtain bootstrap standard errors. With bootstrap standard errors, the results in Table 1 do not change. Both peer-group and shame variables are still statistically significant.

Teenagers are more likely to start having sex if they have a large group of peers who have already had sex and they are less likely to have sex if they are ashamed of it. Several other individual characteristics are considered, such as maternal education, maternal religiosity, whether the respondent lives with two biological parents, whether she has an older sibling, whether she learned about pregnancy or AIDS at school, whether her parents are satisfied with their relationship with the girl, how much parents talk about sex with her, and whether the teenager works and has an independent source of income. ${ }^{5}$ None of these additional factors enter the regression significantly or affect the magnitude and significance of the variables of interest.

5. The basic results in Table 1 also hold with probit or linear probability regressions. In the Online Appendix, Section B, some regression results are reported where instrumental variables are used to mitigate the reflection problem. Shame is still statistically significant but the significance of peer-group effects is weaker. A potential problem in identifying peer-group effects is the presence of correlated effects. Peer 
TABLE 2. Marginal effects.

\begin{tabular}{lc}
\hline & Semi-elasticity \\
\hline School average (peer-group effect) & $0.068(=2.54 / 37)$ \\
Shame & $0.023(=5.2 / 230)$ \\
\hline
\end{tabular}

\subsection{The Import of the Results}

How do peer-group effects and shame affect premarital sex? Given the previous regressions (Table 1, column VI) one can calculate the following marginal effects, expressed in terms of semi-elasticities, displayed in Table 2. A 1\% shift in the shame variable leads to a change in the odds of having premarital sex of 0.023 percentage points. Similarly, a $1 \%$ movement in the school average adjusts the probability of engaging in premarital sex by 0.068 percentage points. This implies that a change of one standard deviation in the school average, which represents a change relative to the mean of $37 \%$, would cause a 2.5 percentage point shift in the odds of engaging in premarital sex. A shift of one standard deviation in the shame factor, which is a change of $230 \%$ (when measured from the mean), is associated with a movement of 5.3 percentage points in this probability. The size of the estimated elasticity for the peer-group effect will be used to discipline the subsequent quantitative analysis. There does not appear to be a natural way to do the same thing with the shame variable, given its ordinal nature.

\section{The Economic Environment}

Imagine a world composed of overlapping generations of females and males. Assume that each female will always give birth at the beginning of adult life to just one set of twins, a male and a female. Thus, there is no aggregate population growth. The birth of the twins may occur in or out of wedlock. Since males play a passive role in the analysis, because they can walk away from an out-of-wedlock birth, they are relegated to the background for the most part. Girls are socialized by their parents. This socialization is important when teenage daughters decide whether or not to engage in premarital sex. A high level of socialization by one's parents will induce a high level of shame if an out-of-wedlock birth occurs. But why should parents socialize their daughters? Altruism is the mechanism here. In particular, later in life, old parents realize utility from the socioeconomic status of the household that their adult daughter lives in. ${ }^{6}$ Since the likelihood of a pregnancy depends on the level of socialization

groups may not be formed randomly. Some additional controls are added to correct for correlated effects. Both shame and peer-group effects are still statistically significant. These results are also reported in the Online Appendix, Section B.

6. The altruism is of an imperfect form. Parents don't take into account the joy their teenage daughters experience from premarital sex. This is probably a better description of the world than assuming that they do. Additionally, altruism is only in one directions - that is, kids do not care about their parents. 
given to a young daughter, young parents will invest resources in it. In the analysis, socialization is a costly activity, so parents undertake it judiciously.

Individuals live for three periods: youth, adulthood, and old age. Females are born with two characteristics: their productivity $y \in \mathfrak{Y} \equiv\left\{y_{1}, \ldots, y_{n}\right\}$, and their libido $l \in \mathcal{R}_{+}$, which represents the utility they realize from sex. The distributions for $y$ and $l$ are given by $Y$ and $L$. The distribution function $L$ is taken to be Weibull and is independent across generations. The distribution for $y$ is conditional on the mother's type-that is, there is some transfer of ability across generations. In particular, $Y\left(y^{\prime} \mid y\right)$ is increasing in $y$, in the sense of stochastic dominance. Because the birth rate for each type of female is fixed, there is no need to keep track of potential shifts in $Y$ over time due to cross-sectional differences in birth rates. Denote the stationary distribution associated with $Y\left(y^{\prime} \mid y\right)$ by $\bar{Y}$. Assume that a suitable law of large numbers holds in this economy and that, consequently, individual probabilities equal aggregate shares of realizations of random variables.

\section{Young Females}

Youths live with their parents. Girls are socialized by their parents at the beginning of their youth. Represent the level of socialization by $s$. This denotes some level of investment that parents make in influencing a daughter's views on premarital sex. The word investment is used deliberately. Noncognitive skills, such as the sense to avoid risky activities like drinking, doing drugs, or engaging in premarital sex, are important for building a child's human capital. They complement the formal schooling stressed by economists. After this socialization occurs, female youths decide whether or not to engage in premarital sex. This is the only decision a young female makes. If they do so, they receive a utility $l \geq 0$, but risk a pregnancy with probability $1-\pi$. Think about $\pi$ as representing the quality of the contraception technology, including more drastic measures, specifically abortion and infanticide. For example, it may be reasonable to view the 1973 decision by the US Supreme Court that legalized abortion as a drop in $1-\pi$.

An out-of-wedlock birth will generate a present value of guilt in the amount $S(s)$. The shame function $S(\cdot)$ is increasing and strictly concave in $s$. If girls do not engage in premarital sex, they get utility normalized to zero. The shame that a girl may suffer from an out-of-wedlock birth may be mitigated by peer-group effects. Let $\boldsymbol{e}$ represent the aggregate number of females in the girl's generation who are engaged in premarital sexual relationships. The peer-group effect will be represented by $P(\boldsymbol{e})$, so that the net shame a girl will suffer from an out-of-wedlock birth is $S(s)-P(\boldsymbol{e})$.

A female will enter adulthood next period with a known level of productivity $y^{\prime}$, and perhaps an out-of-wedlock child. Represent the value function for a female adult next period by $A^{\prime}\left(y^{\prime}, I^{\prime}\right)$, where $I^{\prime}$ indicates whether or not she had an out-of-wedlock birth. In particular, $I^{\prime} \in\{0,1\}$ will return a value of one when an out-of-wedlock birth has occurred. Here a prime is attached to a variable to denote its value in the next period. Likewise, a prime is attached to a function to signify that the implied relation 
changes as time progresses. A precise definition for $A$ will be provided in Section 6. The function will have the properties that $A^{\prime}$ is increasing in $y^{\prime}$ so that higherproductivity girls can expect higher levels of utility vis-à-vis lower-productivity ones. It will also transpire that $A^{\prime}\left(y^{\prime}, 0\right)>A^{\prime}\left(y^{\prime}, 1\right)$, so that an out-of-wedlock birth is costly.

\subsection{Premarital Sex}

Direct attention now to a female youth's decision about whether or not to engage in premarital sex. On the one hand, if a female youth is abstinent, she will realize an expected lifetime utility level of $A^{\prime}\left(y^{\prime}, 0\right)$. On the other hand, if she engages in premarital sex, she will realize the enjoyment $l$ but will become pregnant with probability $1-\pi$. Her expected lifetime utility level will be $l+\pi A^{\prime}\left(y^{\prime}, 0\right)+(1-$ $\pi)\left[A^{\prime}\left(y^{\prime}, 1\right)-S(s)+P(\boldsymbol{e})\right]$. She will pick the option that generates the highest level of expected lifetime utility. Her decision can be summarized as follows:

ABSTINENCE if $A^{\prime}\left(y^{\prime}, 0\right) \geq l+\pi A^{\prime}\left(y^{\prime}, 0\right)+(1-\pi)\left[A^{\prime}\left(y^{\prime}, 1\right)-S(s)+P(\boldsymbol{e})\right]$, PREMARITAL SEX if $A^{\prime}\left(y^{\prime}, 0\right)<l+\pi A^{\prime}\left(y^{\prime}, 0\right)+(1-\pi)\left[A^{\prime}\left(y^{\prime}, 1\right)-S(s)+P(\boldsymbol{e})\right]$.

Pick a row in (2) and fix $y^{\prime}$ and $s$. Observe that the right-hand side is increasing in $l$, while the left-hand side is constant. Thus, there is a threshold for utility from sex for females, $l^{*}$, such that

$$
A^{\prime}\left(y^{\prime}, 0\right)=l^{*}+\pi A^{\prime}\left(y^{\prime}, 0\right)+(1-\pi)\left[A^{\prime}\left(y^{\prime}, 1\right)-S(s)+P(\boldsymbol{e})\right],
$$

or

$$
l^{*}=\mathcal{L}\left(s, \boldsymbol{e}, y^{\prime}\right) \equiv(1-\pi)\left\{S(s)-P(\boldsymbol{e})+A^{\prime}\left(y^{\prime}, 0\right)-A^{\prime}\left(y^{\prime}, 1\right)\right\} .
$$

This expression equates the utility of sex, given by $l^{*}$, with its expected cost, the difference in future expected utilities induced by an out-of-wedlock birth plus the shame, net of peer-group effects, associated with this event, multiplied by the probability of pregnancy. Hence, a threshold rule of the form $l^{*}=\mathcal{L}\left(s, \boldsymbol{e}, y^{\prime}\right)$ obtains such that for $l>\mathcal{L}\left(s, \boldsymbol{e}, y^{\prime}\right)$ the female agent will seek sex and will not otherwise. This threshold is a function of the state of contraceptive technology $\pi$, as can be seen from (3). As the failure rate of contraception, $1-\pi$, declines the threshold value for libido, $l^{*}$, will drop, assuming that $P(\boldsymbol{e})$, and $A^{\prime}\left(y^{\prime}, I^{\prime}\right)$ remain constant.

The odds of a type- $y^{\prime}$ female youth with a socialization level of $s$ engaging in premarital sex are given by

$$
E\left(s, \boldsymbol{e}, y^{\prime}\right) \equiv 1-L\left(\mathcal{L}\left(s, \boldsymbol{e}, y^{\prime}\right)\right)
$$

while the probability of becoming pregnant is

$$
(1-\pi) E\left(s, \boldsymbol{e}, y^{\prime}\right)
$$




\section{Adulthood}

At the start of adulthood, females and males are matched for the rest of their lives. A female will enter a marriage with productivity level $y$, and possibly some outof-wedlock children, represented by $I$. Now, a type- $(y, I)$ female will be matched with a male of productivity, $\tilde{y}$, according to some marriage rule, discussed later. A young married couple realize utility from their match denoted by $U(y, \tilde{y}, I)$. Presume that the felicity of a match is increasing in the productivity of the female, $y$, and of the male, $\tilde{y}$. Higher types will earn more. It also seems reasonable to assume that $U(y, \tilde{y}, 0)>U(y, \tilde{y}, 1)$. An out-of-wedlock birth may prevent a female from realizing the full potential of her productivity. Perhaps she could not fulfill her educational aspirations or had less job experience due to a teenage pregnancy. The male may be less engaged with a daughter who is not his own. Parents also derive expected utility from their daughter, $D\left(y^{\prime}, I^{\prime}\right)$, which is increasing in $y^{\prime}$ with $D\left(y^{\prime}, 0\right)>D\left(y^{\prime}, 1\right)$. This function reflects the daughter's expected standard of living when married. A daughter with an out-of-wedlock birth may earn less and marry a less-desirable husband than a daughter who does not have an out-of-wedlock child. This reduction in her socioeconomic status affects the parents' utility. The function $D\left(y^{\prime}, I^{\prime}\right)$ does not include the enjoyment from sex that a daughter may experience when young. Socializing their daughter involves a cost, the disutility of which is denoted by $V(s)$. The function $V(s)$ is presumed to be increasing and convex in $s$. All of these felicity streams are public goods enjoyed jointly by husband and wife.

Remember that for a female youth the probability of having out-of-wedlock children is $(1-\pi) E\left(s, \boldsymbol{e}, y^{\prime}\right)$. The odds of not having an out-of-wedlock birth are $1-(1-\pi) E\left(s, \boldsymbol{e}, y^{\prime}\right)=1-E\left(s, \boldsymbol{e}, y^{\prime}\right)+\pi E\left(s, \boldsymbol{e}, y^{\prime}\right)$. A teenage girl may not have an out-of-wedlock birth for two reasons: she may stay abstinent, which happens with probability $1-E\left(s, \boldsymbol{e}, y^{\prime}\right)$, or she may engage in premarital sex but not become pregnant, the odds of which are $\pi E\left(s, \boldsymbol{e}, y^{\prime}\right)$. Therefore, the expected level of utility for a young adult couple in a marriage of type $\left(y, \tilde{y}, I, y^{\prime}\right)$, who socialize their daughter to the arbitrary level $s$, will read

$$
\begin{aligned}
M\left(y, \tilde{y}, I, y^{\prime}, s\right)= & U(y, \tilde{y}, I)-V(s)+\left[1-(1-\pi) E\left(s, \boldsymbol{e}, y^{\prime}\right)\right] D\left(y^{\prime}, 0\right) \\
& +(1-\pi) E\left(s, \boldsymbol{e}, y^{\prime}\right) D\left(y^{\prime}, 1\right) .
\end{aligned}
$$

The young adult couple will choose $s$ to maximize their lifetime utility. Hence, $s$ solves

$$
M^{*}\left(y, \tilde{y}, I, y^{\prime}\right) \equiv \max _{s}\left[M\left(y, \tilde{y}, I, y^{\prime}, s\right)\right] .
$$

The function $M^{*}\left(y, \tilde{y}, I, y^{\prime}\right)$ gives the expected value for a type- $(y, I)$ young adult female marrying a type- $\tilde{y}$ young adult male, who together have a type- $y^{\prime}$ daughter. Then, the value function for a young adult female just prior to marriage will read

$$
A(y, I) \equiv \sum_{\tilde{y}} \sum_{y^{\prime}} M^{*}\left(y, \tilde{y}, I, y^{\prime}\right) Y^{m}(\tilde{y} \mid y, I) Y\left(y^{\prime} \mid y\right),
$$


where $Y^{m}(\tilde{y} \mid y, I)$ denotes the conditional odds of a type- $(y, I)$ female drawing a type- $\tilde{y}$ male in the marriage market. These odds are discussed next.

\subsection{Matching Process}

Suppose that the conditional odds of a type- $(y, I)$ female drawing a type- $\tilde{y}$ male in the marriage market are described by the distribution function $Y^{m}(\tilde{y} \mid y, I)$. Presume that the distribution $Y^{m}(\tilde{y} \mid y, 0)$ stochastically dominates $Y^{m}(\tilde{y} \mid y, 1)$. Thus, a girl with an out-of-wedlock birth is less likely to be matched with a high-type male than a girl without one. The precise form of this conditional distribution will depend on the assumed matching process. It will be assumed that a fraction $\mu$ of couples is matched in accordance with the Gale-Shapley (1962) algorithm while the remaining fraction $1-\mu$ is matched randomly. This algorithm computes the utilities from various types of marriages and orders them from the highest down to the lowest. (Remember that all utility flows within a marriage are public goods.) The presence of an out-ofwedlock birth reduces the desirability of a match. The matching process then allocates people into marriages starting with the highest-valued matches and going down the list until everybody is matched. The algorithm tends to match similar types with similar types. Strong assortative mating is not observed in the United States, which explains the inclusion of randomness in the matching process. The details are in the Online Appendix, Section C.1.

\subsection{Solution for Socialization}

The solution to problem $\mathrm{P}(1)$ can now be characterized. Maximizing with respect to $s$ yields the first-order condition

$$
-(1-\pi) E_{1}\left(s, \boldsymbol{e}, y^{\prime}\right)\left[D\left(y^{\prime}, 0\right)-D\left(y^{\prime}, 1\right)\right]=V_{1}(s) .
$$

From the above efficiency condition, it is apparent that the level of socialization for a daughter, $s$, will be a function of her type, $y^{\prime}$, so that $s=\mathcal{S}\left(\mathbf{e}, y^{\prime}\right)$. Using equations (3) and (4) it is easy to see that

$$
-E_{1}\left(s, \boldsymbol{e}, y^{\prime}\right)=L_{1}\left(l^{*}\right)(1-\pi) S_{1}(s) .
$$

Thus,

$$
(1-\pi)^{2} L_{1}\left(l^{*}\right) S_{1}(s)\left[D\left(y^{\prime}, 0\right)-D\left(y^{\prime}, 1\right)\right]=V_{1}(s) .
$$

The left-hand side of this expression gives the marginal benefit from socialization while the right-hand side represents the marginal cost. A drop in the failure rate for contraception, $1-\pi$, reduces the incentive to socialize, ceteris paribus, and should lead to a fall in $s$. Note that the density function for libido, $L_{1}\left(l^{*}\right)$, also enters this expression. This term shows how a change in the threshold $l^{*}$ will shift the odds of a daughter having premarital sex, as represented by $L_{1}\left(l^{*}\right)(1-\pi) S_{1}(s)$. When it is high, shifting the threshold through shaming will have a large effect. Hence, socialization 
pays off. Suppose that the threshold level for premarital sex falls when the failure rate drops. If $L_{1}\left(l^{*}\right)$ is decreasing in $l^{*}$, then this force will operate to increase the parents' desire to socialize their daughter, other things equal.

\section{Perfect Foresight Equilibrium}

Let the economy start off from the stationary productivity distribution $\bar{Y}(y)$. This will be the productivity distribution hereafter. For this section only, let the variable $t$ represent time where $t=1,2, \ldots$. The aggregate number of girls who are engaging in premarital sex during period $t, \boldsymbol{e}_{t}$, will be implicitly determined by

$$
\boldsymbol{e}_{t}=\sum_{y} E_{t}\left(\mathcal{S}_{t}\left(\boldsymbol{e}_{t}, y\right), \boldsymbol{e}_{t}, y\right) \bar{Y}(y) .
$$

The term $E_{t}\left(\mathcal{S}_{t}\left(\boldsymbol{e}_{t}, y\right), \boldsymbol{e}_{t}, y\right)$ gives the period- $t$ odds that a girl of type $y$, who has been socialized to the level $s_{t}=\mathcal{S}_{t}\left(\boldsymbol{e}_{t}, y\right)$ by her parents, will engage in premarital sex. To compute $\boldsymbol{e}_{t}$ just sum over all types of girls, as is done. Note that the functions $E$ and $S$ depend on time, as indicated by the subscript $t$. Let $F_{t+1}$ represent the joint distribution in period $t+1$ for young adult females over $(y, I)$. This distribution will be given by

$$
F_{t+1}(y, 1)=\left(1-\pi_{t}\right) E_{t}\left(\mathcal{S}_{t}\left(\boldsymbol{e}_{t}, y\right), \boldsymbol{e}_{t}, y\right) \bar{Y}(y)
$$

with

$$
F_{t+1}(y, 0)=\bar{Y}(y)-F_{t+1}(y, 1),
$$

where $\boldsymbol{e}_{t+1}$ is defined by (8). Equation (9) gives the number of young girls with a productivity level $y$ that will experience an out-of-wedlock birth in period $t$.

DEFINITION 1. Start the economy off in period 1 with the invariant productivity distribution $\bar{Y}(y)$ and the type distribution for young adult females $F_{1}(y, I)$. Given a perfect foresight sequence of failure rates $\left\{1-\pi_{t}\right\}_{t=1}^{\infty}$, an equilibrium consists of sequences of threshold libido rules for female youths $\left\{\mathcal{L}_{t}\left(s_{t}, \boldsymbol{e}_{t}, y^{\prime}\right)\right\}_{t=1}^{\infty}$, utilities for married young females and teenage girls $\left\{M_{t}^{*}\left(y, \tilde{y}, I, y^{\prime}\right)\right\}_{t=1}^{\infty}$ and $\left\{A_{t}(y, I)\right\}_{t=1}^{\infty}$, rules for how young parents socialize their daughters $\left\{S_{t}\left(\boldsymbol{e}_{t}, y^{\prime}\right)\right\}_{t=1}^{\infty}$, the matching probabilities for an unmarried female $\left\{Y_{t}^{m}\left(\tilde{y}^{\prime} \mid y^{\prime}, I^{\prime}\right)\right\}_{t=1}^{\infty}$, an aggregate level of teenage girls experiencing premarital sex $\left\{\boldsymbol{e}_{t}\right\}_{t=1}^{\infty}$, and stationary distributions for unmarried females $\left\{F_{t}\left(y^{\prime}, I^{\prime}\right)\right\}_{t=2}^{\infty}$, such that

1. The threshold rule for a female youth maximizes her utility, as specified by equation (3).

2. The utilities for young married females and teenage girls are defined by equations $\mathrm{P}(1)$ and (5).

3. The parents' socialization rule maximizes their utility in line with $\mathrm{P}(1)$.

4. The matching probabilities are determined in line with a modified Gale-Shapley matching process described in the Online Appendix, Section C.1. 
5. The number of sexually active teenage girls is represented by equation (8).

6. The distribution for unmarried females is given by equation (9).

\section{Setting up the Simulation}

The model will now be simulated to see if it can explain the rise in premarital sex and the increase in out-of-wedlock births over the last century. Simulating the model requires choosing functional forms and picking parameter values. The functional forms will be selected so that the model maps into an overlapping generations model with three phases of life: youth, adulthood, and old age. They are also picked to satisfy balanced growth. Thus, long-run trends in income will have no impact on sexual practice.

Some parameter values for the model can be taken directly from the literature or the US data. For others, this cannot be done. The strategy adopted here will be to pick these parameters so that a steady state for the model matches some stylized facts for the modern era, or the United States around 2000. In particular, the analysis will be disciplined by calibrating the model to a set of three cross-sectional observations for the modern time, as well as the observed strength of peer-group effects. The fact that the model can do this is not a forgone conclusion. Then, the model will be simulated to see if it can account for the observed rise in premarital sex over the last one hundred years, given the calibrated parameter values and the observed technological progress in contraception.

\subsection{The Parameterization of Functional Forms}

To begin with, the functions $S(s), U(y, \tilde{y}, I), P(\boldsymbol{e}), D\left(y^{\prime}, I^{\prime}\right)$, and $V(s)$ need to be parameterized. Before proceeding, let $\hat{y}(y, I)$ represent the income that a type- $(y, I)$ woman can earn on the labor market. The idea is that a woman's actual productivity $\hat{y}(y, I)$ may differ from her potential productivity $y$ due to an out-of-wedlock birth, denoted by $I=1$. This will be made more precise shortly. Assume that there are $N$ productivity levels for $y$.

1. Let

$$
U(y, \tilde{y}, I)=\left(\beta+\beta^{2}\right) \ln (\hat{y}(y, I)+\tilde{y}) .
$$

This can be thought of as the utility that a married couple will enjoy over two periods of adult life (young and old) when they have a household income of $\hat{y}(y, I)+\tilde{y}$. Here, $\beta$ represents the discount factor. The utility flow is discounted starting from the first period, or teenage life.

2. The functions for shame and peer-group effects are given standard isoelastic representations. The libido distribution is Weibull. This distribution has a flexible density function, which may rise and then fall in $l$, or just fall in $l$, depending on 
parameter values. The functions are

$$
S(s)=\gamma \frac{s^{1-\delta}}{1-\delta}, P(\boldsymbol{e})=\zeta \frac{\boldsymbol{e}^{1-\iota}}{1-\iota}, L(l)=1-\exp \left[-(l / \sigma)^{\eta}\right](\text { with } \eta, \sigma>0) .
$$

3. Set

$$
D\left(y^{\prime}, I^{\prime}\right)=\beta^{2} \varphi \sum_{\tilde{y}^{\prime}} \ln \left(\hat{y}\left(y^{\prime}, I^{\prime}\right)+\tilde{y}^{\prime}\right) Y^{m^{\prime}}\left(\tilde{y}^{\prime} \mid y^{\prime}, I^{\prime}\right) .
$$

The expression gives the expected discounted utility that young parents will realize from an adult daughter of type $\left(y^{\prime}, I^{\prime}\right)$. This utility is a function of the latter's expected standard of living when married. Young parents do not know the type of male, $\tilde{y}^{\prime}$, their daughter will marry. So they take an expectation over all possible marriages knowing that next period their type- $\left(y^{\prime}, I^{\prime}\right)$ daughter will be matched with a type- $\tilde{y}^{\prime}$ husband with probability $Y^{m^{\prime}}\left(\tilde{y}^{\prime} \mid y^{\prime}, I^{\prime}\right)$.

4. Assume

$$
V(s)=-\beta \theta \ln (\omega-s) .
$$

Here $\omega$ denotes the family's endowment of nonworking time. The couple's leisure is given by $\omega-s$.

5. Give the conditional distribution for productivity, $Y\left(y^{\prime} \mid y\right)$, the following simple representation:

$$
\begin{gathered}
y_{i}^{\prime}=y_{i}, \quad \text { with probability } \rho+(1-\rho) \bar{Y}\left(y_{i}\right), \\
y_{i}^{\prime}=y_{j}(\text { for } i \neq j), \quad \text { with probability }(1-\rho) \bar{Y}\left(y_{j}\right),
\end{gathered}
$$

where $\bar{Y}\left(y_{j}\right)$ represents the odds of drawing $y_{j}$ from the stationary distribution. Thus, with probability $\rho$ a daughter will inherit the productivity level of her mother. With probability $1-\rho$ she takes a new draw from the stationary productivity distribution (where she could still draw by chance her mother's type). With this structure, $\rho$ determines the autocorrelation across types over time within a family.

6. Last, how does an out-of-wedlock birth affect a woman's actual productivity? The function mapping a female's potential productivity, $y$, into her actual level, $\hat{y}(y, I)$, is given by

$$
\hat{y}(y, I)= \begin{cases}y & \text { if } I=0, \\ y-T(y) y & \text { if } I=1,\end{cases}
$$

where

$$
T\left(y_{i}\right) y_{i}=\sum_{j=1}^{i} \lambda\left(\frac{y_{j}}{y_{N}}\right)^{\alpha}\left(y_{j}-y_{j-1}\right)+\tau, \text { for } i=1,2, \ldots, N
$$

with $y_{0} \equiv 0$. The function $T\left(y_{i}\right)$ operates as an implicit tax on an out-of-wedlock birth. It does so in a progressive fashion, so that an out-of-wedlock birth has a disproportionately damaging effect on high-type females. With this formulation, the tax function is determined by the three parameters $\tau, \lambda$, and $\alpha$. Taxes start at 
$\lambda\left(y_{1} / y_{N}\right)^{\alpha}+\tau$ and then rise in a progressive fashion (when $\lambda>0$ and $\alpha>1$ ) with income $y_{i}$ (for $i>1$ ). This is vital for explaining the cross-sectional relationship between a girl's education and the likelihood that she will have premarital sex. In fact, note that without this function there would be no cost of having an out-of-wedlock birth; hence, there would be no need for parents to socialize their daughters. This function is also important for determining the degree of assortative mating that is observed in society (conditional on having an out-of-wedlock birth). The model abstracts from any direct costs of raising children. As a result, the role that public policy - for example, the welfare system-has on the incentive to engage in premarital sex is left outside the analysis. One could think of the progressivity in the previously mentioned tax schedule as capturing some of these considerations, albeit in an ad hoc way.

Recall from the historical discussion in Section 2 that pervasive premarital sex is a recent phenomenon in Western societies. It took off only with the contraception revolution that occurred during the 20th century. Living standards rose considerably between 1600 and 1900; however, this did not have an impact on premarital sex. So the functions $U$ and $D$ need to be structured so that increases in income do not affect the likelihood that a teenage girl will engage in premarital sex. The forms adopted in equations (10) and (11) ensure this.

LEMMA 1. (Balanced growth) Suppose that $U$ and $D$ have the parametric forms given in equations (10) and (11). An increase in all $y$ and $\tilde{y}$ by a factor $\chi>1$ has no effect on $s$.

Proof. See the Online Appendix, Section C.2.

REMARK 1. There is no need to allow for lifetime growth in family income; the proof is similar to the one for Lemma 1 on balanced growth.

\subsection{Calibration}

8.2.1. Productivity. The productivity process is calibrated from the US data. The analysis will focus on several stylized facts categorized with respect to a woman's educational background. Hence, a mapping needs to be constructed between educational attainment and productivity. ${ }^{7}$ There will be three groups for educational attainment: namely, less than high school $(<\mathrm{HS})$; high school and some college (HS); college and post-college (C). The productivity distributions for women and men are specified for each category of education. An educational group is divided into six productivity levels corresponding to the average wage rate for those individuals lying within the following ranges for percentiles: 0-10, 10-25, 25-50, 50-75, 75-90, and

7. The data are from the 2000 US Census. The sample consists of men and women between ages 25 and 54 . Hourly wages are calculated by dividing yearly wage and salary income by yearly hours (calculated as weekly hours times weeks worked) and are normalized by the means for wages. 
TABle 3. Productivity distribution.

\begin{tabular}{lccc}
\hline & $y$ (females) & $\tilde{y}$ (males) & Fraction of females and males \\
\hline$<$ HS & 0.49 & 0.72 & 0.123 \\
HS & 0.72 & 0.98 & 0.607 \\
C & 1.14 & 1.43 & 0.270 \\
\hline
\end{tabular}

Note: Means, tabulated from 2000 US Census.

90-100. Thus, there are in all 18 productivity levels for each sex; hence, $N=18$. The ranking of income levels does not map monotonically into education groups. For example, women in the upper end of the high school pay scale earn more than those at the lower end of the college scale. This procedure is a variation on the one employed in Guner, Kaygusuz, and Ventura (2012). The parameterization adopted for the stationary distribution, $\bar{Y}$, is summarized in Table 3, which shows the mean level of productivity for each education group. The figures have been normalized by the mean wage rate for the entire sample. Following Knowles (1999), set the intergenerational persistence in productivity across generations of females at 0.70 , so that $\rho=0.7$.

8.2.2. Contraception. The annual failure rate for contraception in 2002 was $28 \%$. A detailed discussion about the failure rate series shown in the left panel of Figure 1 is contained in Greenwood and Guner (2010), but in a nutshell, the idea is to combine information on the usage of different contraceptives at first premarital intercourse together with statistics on the effectiveness of each type of contraception. In 2002 , for example, $51.2 \%$ of girls used condoms in their first premarital intercourse, and these condoms were about $85 \%$ effective (which represents the odds of not becoming pregnant over a year with typical use). An aggregate effectiveness measure is constructed by taking a weighted sum of effectiveness over all different contraception methods (e.g., condoms, the pill, withdrawal, etc.). Not using any contraception at all is included an as option as well. The measure assumes that a girl is sexually active for a year.

This annual failure for 2002 must be converted into an effective failure rate over teenage life, taken to be ages 14 to 19 . An average teenager does not engage in premarital sex most of the time. A sizable majority of 15- to 17-year-old females have not experienced sex, while most of 18- to 19-year-olds have; see Abma, Martinez, and Copen (2010, Table 9). Plus, teenage relationships are short. Let $\kappa$ represent the fraction of a typical year, in the 14-19 age interval, that a teenage girl is sexually active. Then, the odds of not becoming pregnant by the end of this six-year interval are $(1-0.28 \kappa)^{6}$. Data from the 2002 National Survey of Family Growth (NSFG) are used in what follows to calibrate the cross-sectional relationship between a girl's education and the likelihood that she will have premarital sex. These data suggest that roughly $65 \%$ of girls were sexually active by age $19 .{ }^{8}$ Approximately $13 \%$ of

8. This number underestimates the number of girls who had premarital sex by age 19 for 2002. From the survey, data for women between ages 20 and 44 are used. This age group was chosen to ensure that 
TABLE 4. Targets, data, and model.

\begin{tabular}{|c|c|c|c|c|c|c|}
\hline \multirow[b]{2}{*}{ Premarital sex } & \multicolumn{3}{|c|}{ Data } & \multicolumn{3}{|c|}{ Model } \\
\hline & $\begin{array}{l}<\mathrm{HS} \\
0.73\end{array}$ & $\begin{array}{r}\text { HS } \\
0.71\end{array}$ & $\begin{array}{l}\mathrm{C} \\
0.50\end{array}$ & $\begin{array}{l}<\mathrm{HS} \\
0.79\end{array}$ & $\begin{array}{r}\text { HS } \\
0.66\end{array}$ & $\begin{array}{l}\text { C } \\
0.49\end{array}$ \\
\hline \multicolumn{7}{|c|}{ Source: NSFG 2002} \\
\hline \multicolumn{6}{|c|}{ Source: ATUS 2003} & 0.055 \\
\hline Matching correlation & $\begin{array}{c}\text { No Owb } \\
0.49\end{array}$ & & $\begin{array}{l}w b \\
0.29\end{array}$ & $\begin{array}{c}\text { No Owb } \\
0.50\end{array}$ & & $\begin{array}{l}\text { Owb } \\
0.32\end{array}$ \\
\hline Peer-group effect & \multicolumn{3}{|c|}{$\begin{array}{c}0.068 \\
\text { Source: see Section } 3\end{array}$} & & 0.068 & \\
\hline
\end{tabular}

girls became pregnant by this age in 2006-2008; see Abma, Martinez, and Copen (2010, Table 17). Therefore, in order to be consistent with the observed 2002 level of premarital sex and the 2006-2008 level of teenage pregnancies, $\kappa$ must solve the equation $\left[1-(1-0.28 \kappa)^{6}\right] \times 0.65=0.13$, which implies a value for $\kappa$ of 0.13 . The effective six-year failure rate is $1-(1-0.28 \kappa)^{6}=0.20$. This failure rate is consistent, by construction, with the observed levels of premarital sex and teenage pregnancies. So, for the modern era $\pi=1-0.20=0.80$ - that is, the odds of a sexually active teenager not becoming pregnant over the course of teenage life are $80 \%$.

8.2.3. The Choice of Parameter Values and the Calibration Targets. There are 14 parameter values to determine, $\{\beta, \varphi, \zeta, \gamma, \delta, \theta, \iota, \omega, \mu, \alpha, \tau, \lambda, \eta, \sigma\}$. The time period for the model is six years, which represents the length of teenage life (14 to 19). Taking 0.96 as a standard value for the yearly discount factor, let $\beta=0.96^{6}$. A person is assumed to spend $40 \%$ of her/his time endowment working so set $\omega=1-0.4$. The remaining parameters are picked so that the model's steady state for the modern era matches the four sets of targets discussed in what follows. Given the complex nature of the system under study, there is not a simple one-to-one mapping between a parameter and a data target. Still, some intuition can be provided about how the parameters operate.

1. The cross-sectional relationship between a girl's education and the likelihood that she will have premarital sex. The odds of premarital sex decrease with education, as can be seen from Table 4. The calibrated model matches this cross-sectional feature of the data reasonably well, as can also be seen from Table 4 . About $73 \%$ of girls with less than a high school education engage in premarital sex in the United

the sample size is large enough in order to calculate the fraction of girls who had sex by age 19 by their educational attainment (see Table 4). Older generations of women in the sample were less likely to have had a sexual relationship by age 19 than younger ones. This explains the difference between the $75 \%$ rate shown in Figure 1 for 2002 and the $65 \%$ rate used. 
States. The corresponding figure for the model is $79 \%$. By contrast, roughly $50 \%$ of college-educated girls had such an experience, in both the data and the model. Overall, about $65 \%$ of girls have premarital sex in the United States. The number for the model is $64 \%$. The tax parameters $\tau, \lambda$, and $\alpha$ are vital here because they determine how the girls of various types are affected by an out-of-wedlock birth, both directly through their own future productivity and via the type of husband they will attract in the marriage market. The parameters of the libido distribution, $\eta$ and $\sigma$, are obviously important because they will govern the flow of girls into premarital sexual activity as the cost of this activity falls.

2. The amount of time that a mother spends with her child, as a function of the mother's educational background. Time spent increases with education, as Table 4 illustrates. The data represent the total time spent by a mother with her child on educational and recreational activities (calculated using data from the 2003 American Time Use Study (ATUS)). There are no data available on the time spent socializing a child about sexual matters or values in life, per se. Thus, an assumption is being made that the time spent socializing a child is proportional to the total educational and recreational time spent with a child. The model is good at mimicking this cross-sectional feature of the data too, as can be seen from the table. The parameters $\varphi$ and $\theta$ are key here. They determine how parents care about their daughters $(\varphi)$ and how costly socialization is $(\theta)$.

3. The correlation between a husband's and wife's education, conditional on the presence of an out-of-wedlock birth. This correlation is examined separately for women with and without out-of-wedlock births. The match between the data and the model is shown in Table 4. The model has little trouble reproducing the facts. Recall that the parameter $\mu$ controls the degree of assortative mating. It is important for matching the correlation between a husband's and wife's education, especially in the absence of an out-of-wedlock birth. The presence of an out-of-wedlock birth reduces the degree of assortative mating. The tax parameters $\tau, \lambda$, and $\alpha$ impinge directly on this target, by determining the worth of a woman, with and without an out-of-wedlock birth, in the marriage market.

4. The impact of peer-group effects on the likelihood of engaging in premarital sex. The last target is the semi-elasticity for the peer-group effect estimated in Section 3. This elasticity measures the strength of the peer-group effect in the data and is used to discipline the magnitude of the effect in the model. The model hits this target almost exactly; see Table 4. Not surprisingly, this fact helps to tie down the peer-group parameters $\zeta$ and $\iota$.

The parameter values for the model are listed in Table 5. The implicit tax schedule on an out-of-wedlock birth by (potential) education class is $T(<\mathrm{HS})=0.24$, $T(\mathrm{HS})=0.36$ and $T(\mathrm{C})=0.53$. It weighs high on a young woman at the upper end of the education scale. It is interesting to note that the likelihood that a teenage girl will feel "very upset" if she gets pregnant increases with her mother's educational background, as the left panel of Figure 3 makes clear. The right panel plots for the 
TABLE 5. Parameter values.

\begin{tabular}{ll}
\hline \multicolumn{1}{c}{ Tastes } & \multicolumn{1}{c}{ Matching } \\
\hline$\beta=(0.96)^{6}, \theta=0.27$ (discounting and leisure) & $\mu=0.845$ (fraction assortative) \\
$\varphi=2.41($ altruism) & Tax Schedule \\
$\gamma=5.75, \delta=0.35$ (shame) & $\alpha=4,400, \lambda=5.12, \tau=0.058$ \\
$\zeta=0.138, \iota=0.44$ (peer group) & Libido \\
Productivity & $\eta=1.105, \sigma=0.45$ (Weibull) \\
$y_{i}=$ see Table 3 for average values. & Contraception \\
$\rho=0.70$ (persistence) & $\pi_{2000}=0.80$ (odds safe sex) \\
$\omega=0.6$ (nonworking time) & $\kappa=0.13$ (sexually active period) \\
\hline
\end{tabular}
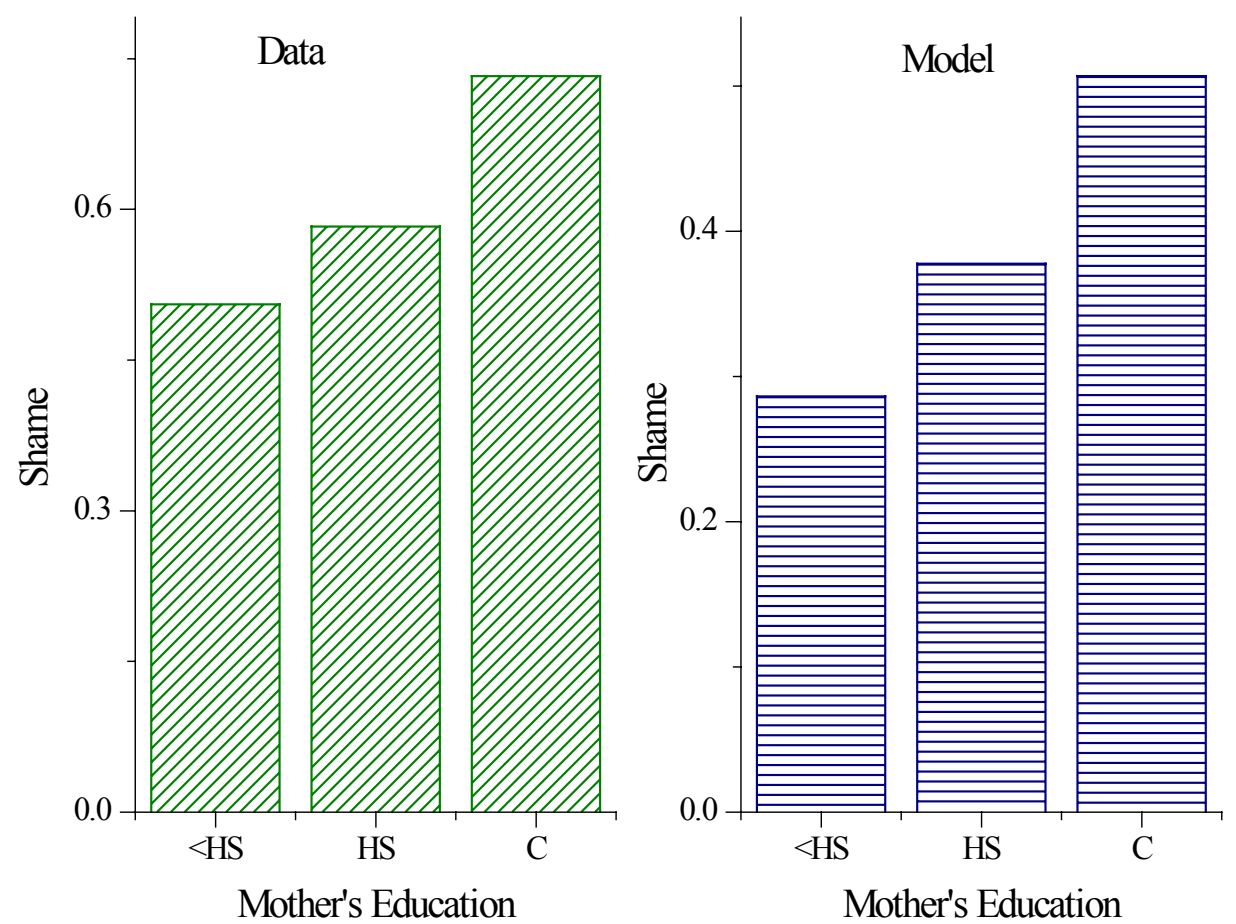

FIGURE 3. Cross-sectional relationship between the daughter's shame from an out-of-wedlock birth and her mother's educational background. The left panel shows the relationship for the data, while the right panel plots it for the model. For the model, shame is measured by $(1-\pi) \sum_{y} S(\mathcal{S}(\boldsymbol{e}, y)) \bar{Y}(y)$ divided by the median level of libido, $\sigma \ln (2)^{1 / \eta}$.

model a measure of the expected shame associated with premarital sex. The required expected level of shame is about $40 \%$ of the median joy from sex. ${ }^{9}$ This seems reasonable.

9. The average expected level of shame in the model is given by $(1-\pi) \sum_{y} S(\mathcal{S}(\boldsymbol{e}, y)) \bar{Y}(y)$. Normalize this by the median level of libido for a Weibull distribution, which is given by $\sigma \ln (2)^{1 / \eta}$. 
8.2.4. Four Comparative Statics Exercises. First, is the future income that a woman earns important for her decision to engage in premarital sex? To answer this, consider eliminating the gender gap between women and men. Women earn about $75 \%$ of what men do in the model. Eliminating the gender gap lowers the rate of premarital sex in the 2000 steady state from $64 \%$ to $61 \%$. Women contribute more to family income, which raises the cost of an out-of-wedlock birth. Alternatively, if a woman earns $50 \%$ of what a man does then the rate of premarital sex would be $74 \%$. Second, reducing the effective tax rate on an out-of-wedlock birth by $50 \%$ raises premarital sexual activity from $64 \%$ to $90 \%$. Clearly, this reduces the cost of engaging in premarital sex. Third, how important is assortative matching in the model? This can be gauged by setting $\mu=0$, so that all matches are random. The cost of an out-of-wedlock birth due to assortative mating drops. For the 2000 steady state, the fraction of women engaging in premarital sex increases from $64 \%$ to $71 \%$. Fourth, consider undertaking a mean-preserving spread in the type distribution across women. In particular, increase the standard deviation by $20 \%$. The premarital sex rate rises from $64 \%$ to $73 \%$, as a consequence. A high-type woman will have to step down relatively less far on the matching ladder when she has an out-of-wedlock birth because her income will still exceed what a low type earns. Reducing the standard deviation by $20 \%$ lowers the rate to $55 \%$.

\section{The Computational Experiment}

Imagine starting the world off in a situation where premarital sex is risky. Specifically, assume that the annual failure rate for contraception is $72 \%$ in the economy's initial position; this is Greenwood and Guner's (2010) estimate for 1900. Following the earlier analysis, this implies that the odds of safe sex are $(1-0.72 \kappa)^{6}=0.55$, where again it is assumed that a girl who engages in premarital sex will only be sexually active $13 \%$ of the time in a typical year-that is, $\kappa=0.13$. A series for the odds of safe sex is constructed, based on the failure rate series in Figure 1, that rises over time from $55 \%$ to $80 \%$ - the number picked earlier for $2000 .{ }^{10}$ The odds of safe sex rose for three reasons. First, over time, there was a rise in the number of teenagers who use some form of contraception. The number of teenagers using some method increased from $40 \%$ to $80 \%$ between 1900 and 2002, perhaps due to better information offered by birth control clinics, doctors, schools, and so forth. Second, the effectiveness of any given method tended to rise. Third, new methods, such as the pill, became available, although the pill had a very marginal impact on teenagers given its limited use; again, see Greenwood and Guner (2010) for more information. The inputted time profile for the odds of safe sex is displayed in the left panel of Figure 4. Individuals have perfect foresight about this path. The estimated effectiveness of contraceptives increases pretty

10. The annual failure rates from Figure 1 are $72 \%$ in $1900,59 \%$ in $1960-1964,54 \%$ in $1965-1969$, $53 \%$ in $1975-1979,48 \%$ in $1980-1982,37 \%$ in $1983-1988,34 \%$ in $1990-1994$ and $28 \%$ in 2002 . The odds for safe sex in Figure 4 reflect these failure rates, with the additional assumption that the failure rates decline linearly between 1900 and 1960 . 


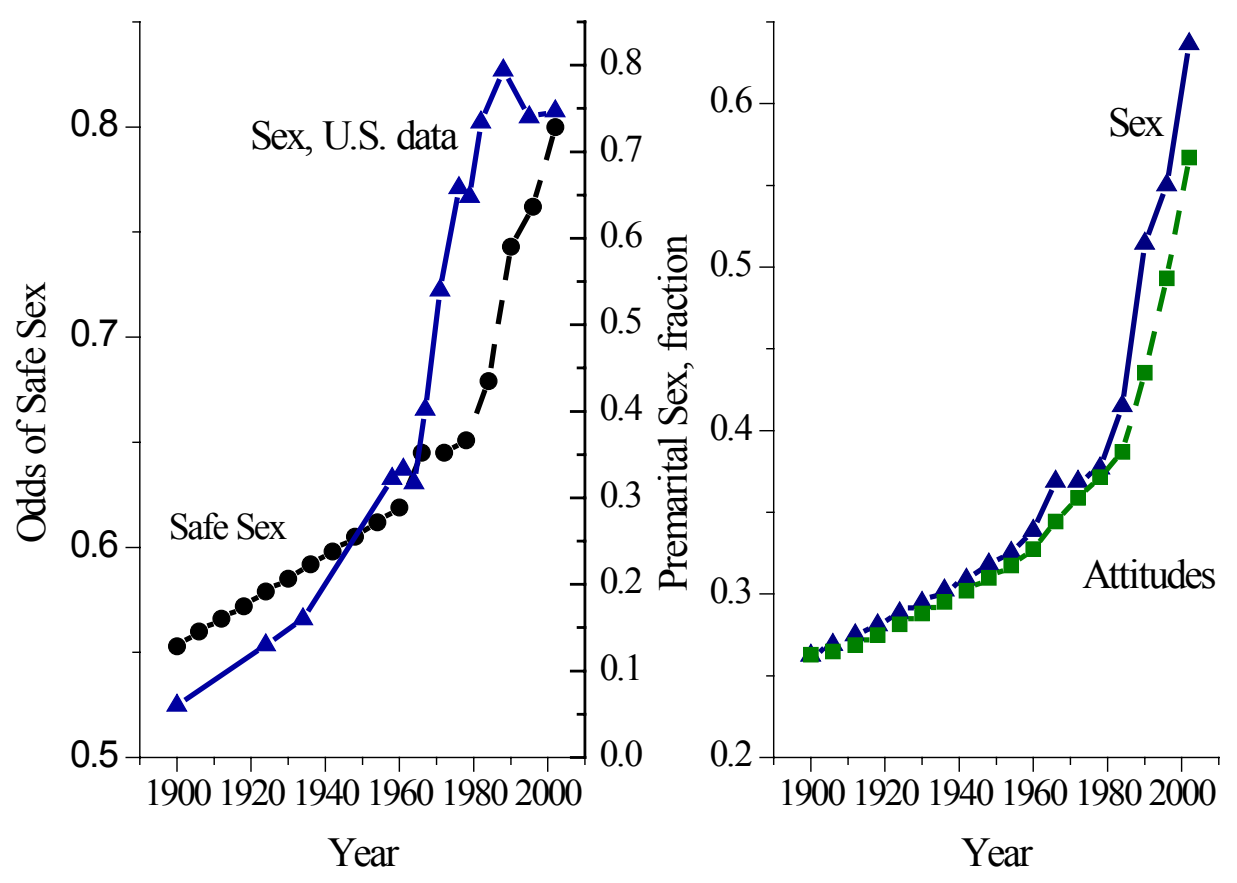

FigURE 4. Sexual revolution.

steadily between 1900 and 2002 (Figure 4). So, what will happen in the economy under study?

The increase in the efficacy of contraception induces a sexual revolution in the model, which is displayed in the right panel of Figure 4 . The number of women practicing premarital sex rises from $26 \%$ to $64 \%$, matching qualitatively the pattern displayed in the US data (which are displayed in the left panel of the figure). ${ }^{11}$ The initial level of premarital sex is too high, though (26\% versus $6 \%)$; more on this later. It is reasonable to postulate that the number of women engaging in premarital sex proxies for the fraction of that generation that has a favorable attitude toward it. At any point in time, society is made up of many generations of women, each of which had a different sexual experience. Averaging across all generations gives a measure of society's attitude toward premarital sex. Do this for the three generations in the model. As can be seen, attitudes lag current sexual practice. This is due solely to a cohort effect. ${ }^{12}$ Additionally, as contraception becomes more effective, parents socialize their daughters less (Figure 5).

11. For 2002 the model predicts a premarital sex rate of $64 \%$, while in the data it is $75 \%$. Footnote 8 provides an explanation for this difference.

12. See footnote 16 for an illustration of how stigma may be transmitted over time. This leads to persistence in parents' socialization decisions. 


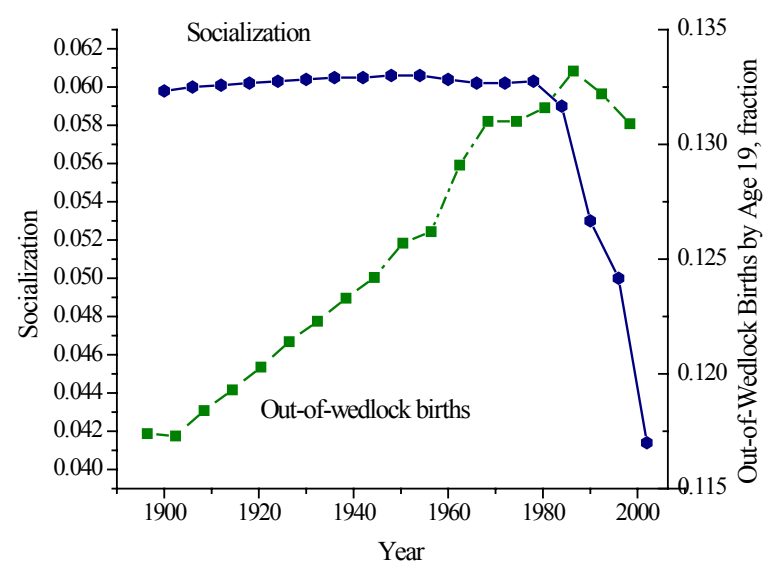

FIGURE 5. The decline in socialization and the rise in out-of-wedlock births.

The socialization series has an interesting pattern. It is flat until the 1980s and then shows a dramatic decline. It is as if sexual mores have suddenly changed due to a revolution in attitudes. The decline in the odds of pregnancy, $1-\pi$, reduces the incentive to socialize, as is apparent from the first-order condition (6). But it also lowers the threshold value for premarital sex, $l^{*}$, which entices more girls to engage in this activity. This can increase the density function, $L_{1}\left(l^{*}\right)$, which measures the impact of a shift in the threshold on the odds of a girl engaging in premarital sex. It then pays for parents to socialize their daughters more in order to raise this threshold and dissuade them from having premarital sex. These two effects cancel each other out until the 1980s. The number of out-of-wedlock births rises in the model. In particular, they increase from $11.7 \%$ to $13.1 \%$. This series is not directly comparable to the one presented in Figure 1. The series for the US data gives the fraction of teenagers who became pregnant in a given year. For the model, the series shows the fraction of teenagers who became pregnant by age 19. Unfortunately, a time series for this isn't available in the data. The pregnancy rate using the latter notion will be higher than the former one. Still, the initial pregnancy rate looks too high for the model. This occurs because too many girls in the model are engaging in premarital sex. The extension developed in Section 10 helps a lot with this shortcoming.

\subsection{The Importance of Socialization and Peer-Group Effects: Some Counterfactual Experiments}

One can ask how important in the model is socialization for curtailing premarital sex. To gauge the significance of this, three counterfactual experiments are run. First, one could ask what would happen if parents did not socialize their children at all $(s=0)$. The results of this experiment are shown in the top line of the left panel of Figure 6. As can be seen, promiscuity would run rampant in the model. Even in the old steady 

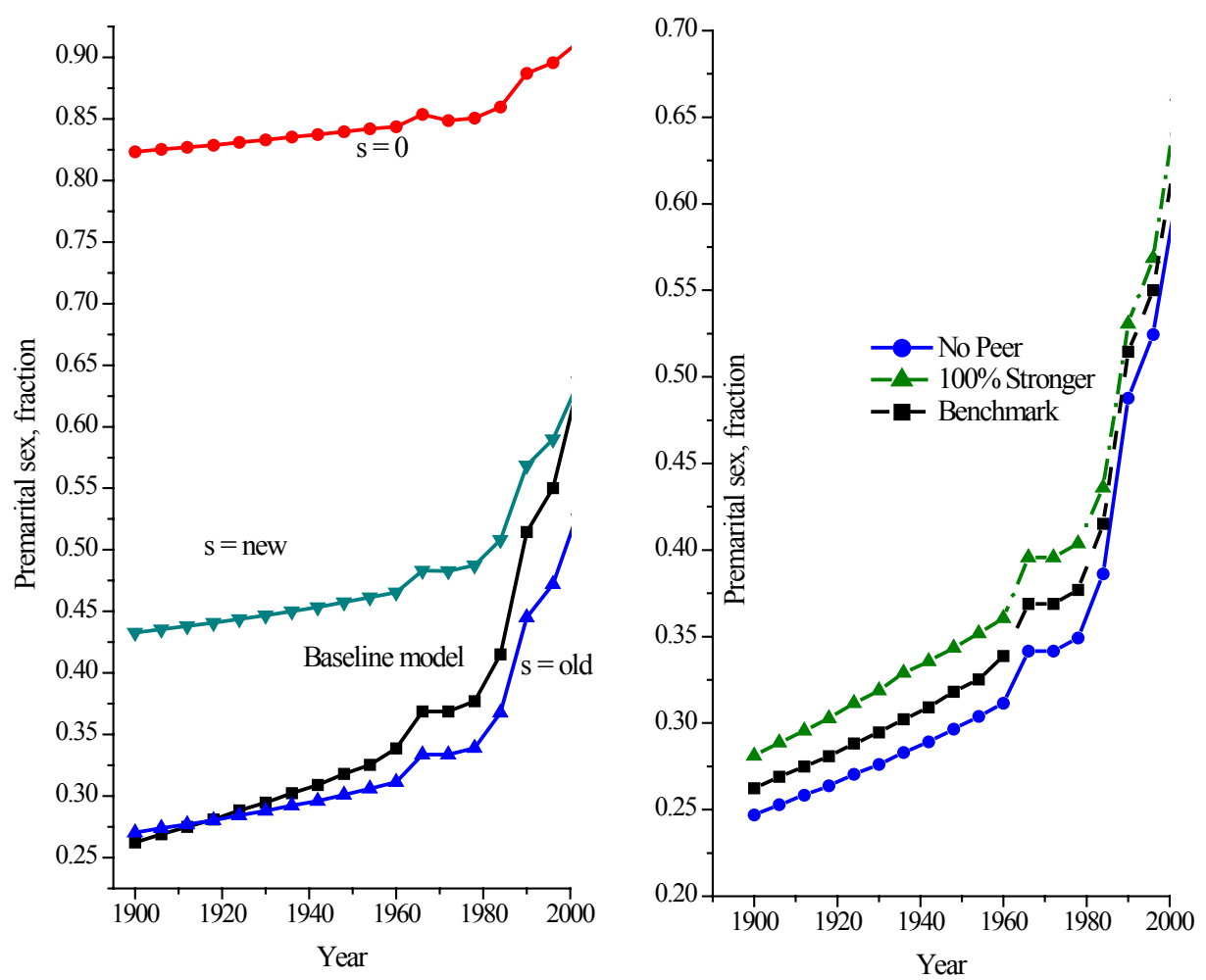

FIGURE 6. Left: the effect of socialization on premarital sex. Right: the impact of peer-group effects on premarital sex.

state $82 \%$ of girls would engage in premarital sex. A large fraction of these girls would become pregnant, given the poor state of contraception. This compares with roughly $26 \%$ in the baseline model. Second, one could ask what would happen if parents maintained their old steady-state levels of socialization $(s=$ old $)$ even in the face of technological improvement in contraception. As can be seen from the bottom line, a substantial minority of girls (47\%) would remain abstinent in the new steady state. These two experiments suggest that socialization plays an important role in the model. Third, the line labeled $s=n e w$ plots the transitional dynamics for model in the situation where parents always follow the new steady-state pattern of socialization. Here $43 \%$ of girls would engage in premarital sex in the initial period (again compared with $26 \%$ in the baseline model). Thus, the transitional dynamics to the new steady state are slower than in the baseline model — that is, the decline in socialization speeds up the transition in the baseline model.

The importance of peer-group effects will now be assessed. This is done by shutting them down in the model (by setting $\zeta=0$ ). Additionally, the implied semielasticity for the peer group in the model is increased by roughly $100 \%$ (which requires $\zeta=0.285$ ). The size of this semi-elasticity is roughly two standard deviations above the 


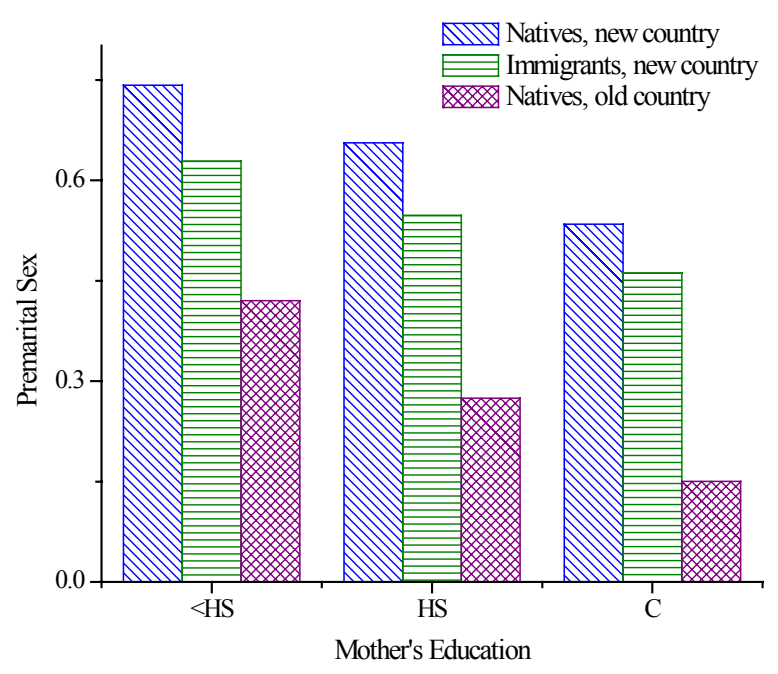

FIGURE 7. The cross-sectional odds of premarital sex in the immigration thought experiment.

magnitude estimated in the US data. As can be seen from the right panel of Figure 6, while the prevalence of the peer group definitely increases the equilibrium level of premarital sex, the impact is quite moderate. In the benchmark analysis, the level of premarital sex in the final steady state is $64 \%$ with peer-group effects. This compares with $61 \%$ without them and $66 \%$ when their strength is doubled. In the analysis the size of peer-group effects is disciplined by estimating the semi-elasticity from the US data (Table 2). While statistically quite significant, the estimated elasticity is small. So, this limits the importance of peer-group effects in the model. Still, they are present. In a similar vein, while the presence of peer groups increases the amount of socialization done by parents, the effect is quite small.

9.1.1. Immigration Thought Experiment. To cast further light on the importance of socialization, imagine that a teenage girl grows up in a nation (the old country) with a primitive state of contraception $(\pi=0.55)$. Her parents socialize her according to the environment there. Now, suppose that at around 15 years of age the girl and her family immigrate to another nation (the new country) with a more advanced state of contraception $(\pi=0.80)$. In the new country the teenager will decide whether or not to engage in premarital sex. She will do this so as to maximize her lifetime utility, taking into account: (i) the odds of becoming pregnant; (ii) how a pregnancy will affect her new-country socioeconomic status; (iii) how becoming pregnant will relate to her old-country set of values; and (iv) what her new peers are doing. Figure 7 illustrates the upshot of this thought experiment. The young teenager's odds of engaging in premarital sex decrease as a function of her mother's education. In general, a girl whose mother is educated has more to lose from engaging in this risky activity than one whose mother is not. Note that an immigrant is less likely to engage in premarital sex than a native in 
the new country is, at all education levels. Native girls in the new country received less socialization about the perils of premarital sex than the immigrant did. Their parents are more liberal about this, because the risk of becoming pregnant is much less in the new country versus the old country. Likewise, girls who remain in the old country will be less likely to be sexually experienced relative to an immigrant to the new country, both because the risk of pregnancy is higher in the old country and the peer-group effects are weaker. Culture affects decisions, but the economic environment also affects culture.

\section{The Church and State: An Extension}

\subsection{Historical Discussion}

Illegitimacy imposes a financial burden on state and church. Different European states organized and funded orphanages and conservatories that took care of abandoned children, mostly illegitimate ones; see, for example, Sherwood (1989) who discusses Spain. Churches, as long as they underwrote charity work, faced a similar burden. To avoid these financial costs, both churches and states have used over history extensive instruments to reduce premarital sex and illegitimacy. Section 2 discussed how states employed criminal procedures to punish premarital sex. But other tools were available. One particularly powerful one was the legal concept of illegitimacy. Both in civil law and common law countries, a child was illegitimate if it was born to parents who were not legally married to one another at the time of the birth, even if they later married. Illegitimate children were subject to a large number of discriminatory measures, from merely symbolic (such as stating on the child's birth certificate his or her condition as illegitimate) to reduced inheritance rights (see Beckert 2008; Witte 2009). ${ }^{13}$ The most harsh of those was the English common law idea of filius nullius (child of nobody): having no right to inherit from either father or mother, no right to the surname of either parent, and no claim on them for support or education. Interestingly enough, these legal mandates were explicitly justified as a way to prevent premarital sex. As the Earl of Selborne states in Clarke v. Carfin Co. (1891), A.C. 412, 427, this policy was designed for "the encouragement of marriage and the discouragement of illicit intercourse."

Illegitimacy taxed the resources of church and state. A fine, called a leyrwite, was levied on the bondwomen of medieval English manors. The name describes its purpose and is based on two Anglo-Saxon elements: "leger" to lie down and "wite" a fine. This tax on fornication (6d versus a daily wage of 3/4d) levied by the Lord and Lady of the manor was aimed at discouraging bastardy, which placed great financial strain on the manorial community; see Bennett (2003). (The Church punished fornicators more ruthlessly.) A related fine was childwite, which was levied on out-of-wedlock births.

13. A simple way to keep the stigma of illegitimacy public existed in Spain. By tradition, in daily life children use the family name of both the father and the mother. Women do not take the family name of their husband when they marry. Consequently, any person who used exclusively his mother's family name was immediately identified as illegitimate. 
TABLE 6. Religiosity and the incidence of premarital sex.

\begin{tabular}{llc}
\hline Religiosity & Girl's & Parents' \\
\hline Very important & $36.5 \%$ & $40.4 \%$ \\
Fairly important & 47.0 & 44.4 \\
Fairly unimportant & 47.2 & 47.8 \\
Not important at all & 47.8 & 62.7 \\
\hline
\end{tabular}

Stone (1977) relates how parish authorities in England frequently worked to ensure that bastards were born outside of their local jurisdictions, so that they would not have to absorb a financial liability. Hayden (1942-1943) discusses a similar situation in 18th-century Ireland. Churchwardens often employed a "parish nurse". This person was commonly known as a "lifter". Her task was to round up secretly abandoned foundlings and deposit them in a nearby parish. Sometimes she sedated the baby with a narcotic, diacodium, to muffle any crying. One woman, Elizabeth Hayland in the Parish of St John's, lifted 27 babies in a year. Seven died in her care. A baby that she dropped off in the Parish of St. Paul's was promptly returned by its lifter-the churchwarden then told her not to deposit babies at the same place too often. Her salary for lifting was $£ 3$ a year. Another nurse, Joan Newenham, started out getting paid 4s $9 \mathrm{~d}$ for every baby she lifted. This was subsequently switched to an annual salary of $£ 4$ 10s. Illegitimacy placed a great strain on the church's or state’s finances. They may be called upon to provide poor relief to an unwed mother who kept her illegitimate children. They had to support the foundling hospitals and workhouses that received the abandoned babies and provide the children with the necessary food, clothing, wetnursing, and so forth. And then there was the cost of foster parents, orphanages, and workhouses for the lucky children who survived.

\subsection{Evidence on Religiosity and Premarital Sex in the United States, 1994}

Even during modern times there is a connection between religiosity and premarital sex. Table 6 presents the percentage of teenagers who have experienced premarital sex broken down by their religiosity. As can be seen, only $36.5 \%$ of girls who reported that religion was very important in their lives had engaged in premarital sex versus $47.2 \%$ who said that it was fairly unimportant. ${ }^{14}$ Likewise, of those girls whose parents stated that religion was important, only $40.4 \%$ had experienced premarital sex versus $47.8 \%$ for those who said it was fairly unimportant. A similar picture emerges when religiosity is measured by either the frequency of church attendance or praying. The correlation between parents' religiosity and their income is very weak in the US data (Add Health), 0.10 to be specific. Similar correlations are found for the other measures of religiosity. This fact will be referred to later to motivate the setup used in the extension.

14. The numbers of girls sampled in the two not-important-at-all cells are too small to be reliable. 


\subsection{The Extension}

Suppose that church or state officials desire to minimize the current number of out-ofwedlock births. To do this, assume that they embark on a program to encourage parents to socialize their children about the perils of premarital sex. Specifically, let an old couple feel opprobrium in the amount $O(\boldsymbol{r})=\kappa \boldsymbol{r}$, with $0 \leq \kappa$, should their daughter experience an out-of-wedlock birth, where $\boldsymbol{r}$ is the level of activity undertaken by the state or church to generate this stigma. Given the weak correlation between religiosity and income, it will be assumed that the church and state direct their activities toward the population at large - that is, they do not target particular subgroups. Suppose that the church or state faces the linear cost function $v \boldsymbol{r}$, with $v \geq 0$. Clearly, the church and state may pursue other ideals, such as the well-being of society. The virtue of the specific objective adopted here is its simplicity.

The mathematical transliteration of the church's goal is

$$
\min _{\boldsymbol{r}}\left\{\sum_{y^{\prime}}(1-\pi) E\left(s, \boldsymbol{e}, y^{\prime}\right) \bar{Y}\left(y^{\prime}\right)+v \boldsymbol{r}\right\},
$$

subject to

$$
-(1-\pi) E_{1}\left(s, \boldsymbol{e}, y^{\prime}\right)\left[D\left(y^{\prime}, 0\right)-D\left(y^{\prime}, 1\right)+O(\boldsymbol{r})\right]=V_{1}(s), \quad \text { for all } y^{\prime},
$$

taking as given $Y^{m \prime}\left(\tilde{y}^{\prime} \mid y^{\prime}, I^{\prime}\right)$ and $\boldsymbol{r}^{\prime}$. The constraint is the first-order condition that parents solve this period to determine $s$. Note the presence of the opprobrium that they will feel if their daughter has an out-of-wedlock birth. The variables $s$ and $\boldsymbol{e}$ are implicit functions of $\boldsymbol{r}$, as is made clear in what follows. For simplicity, in this formulation the church neglects the secondary impact that its actions may have on the marriage market through the matching function $Y^{m^{\prime}}\left(\tilde{y}^{\prime} \mid y^{\prime}, I^{\prime}\right)$. This channel is complicated to analyze..$^{15}$ So, view the extension here as an illustrative example of how the church or state might be incorporated into the analysis.

Minimizing gives the first-order condition

$$
-(1-\pi)\left\{\sum_{y^{\prime}} E_{1}\left(s, \boldsymbol{e}, y^{\prime}\right) \frac{d s}{d \boldsymbol{r}} \bar{Y}\left(y^{\prime}\right)+\sum_{y^{\prime}} E_{2}\left(s, \boldsymbol{e}, y^{\prime}\right) \frac{d \boldsymbol{e}}{d \boldsymbol{r}} \bar{Y}\left(y^{\prime}\right)\right\}=v,
$$

where

$$
\begin{aligned}
\frac{d s}{d \mathbf{r}}= & \frac{(1-\pi) E_{1}\left(s, \boldsymbol{e}, y^{\prime}\right) O_{1}(\boldsymbol{r})}{\Delta} \\
& +(1-\pi) E_{12}\left(s, \boldsymbol{e}, y^{\prime}\right) \frac{d \boldsymbol{e}}{d \boldsymbol{r}} \times \frac{\left[D\left(y^{\prime}, 0\right)-D\left(y^{\prime}, 1\right)+O(\boldsymbol{r})\right]}{\Delta},
\end{aligned}
$$

15. To understand the problem note that the church's actions today will affect tomorrow's type distributions $F^{\prime}\left(y^{\prime}, I^{\prime}\right)$. This will have an impact on the matching function $Y^{m^{\prime}}\left(\tilde{y}^{\prime} \mid y^{\prime}, I^{\prime}\right)$ described in the Online Appendix, Section C.1. Characterizing the impact of $F^{\prime}$ on $Y^{m^{\prime}}$ involves perturbing a function with respect to a function. Note that $Y^{m^{\prime}}\left(\tilde{y}^{\prime} \mid y^{\prime}, I^{\prime}\right)$ enters into both $E\left(s, \boldsymbol{e}, y^{\prime}\right)$ and $D\left(y^{\prime}, I^{\prime}\right)$. 
with

$$
\Delta \equiv-(1-\pi) E_{11}\left(s, \boldsymbol{e}, y^{\prime}\right)\left[D\left(y^{\prime}, 0\right)-D\left(y^{\prime}, 1\right)+O(\boldsymbol{r})\right]-V_{11}(s)<0,
$$

and

$$
\frac{d \boldsymbol{e}}{d \boldsymbol{r}}=-\frac{v}{(1-\pi)}(\text { using equations (8) and (13)). }
$$

In its calculus the church takes into account how its action $r$ will impact parental socialization decisions $s$ and the peer-group effect $\boldsymbol{e}$. These are the first and second terms on the left-hand side of the first-order condition (13), respectively. Furthermore, it also takes into consideration how a change in peer-group effects $\boldsymbol{e}$ will influence parental actions $s$, as the second line in (14) makes clear. By pressuring parents, the church can increase the amount of socialization they will undertake. The peer-group effect enters as an externality in daughters' and parents' decision making. The church or state has some power to influence this external effect, though, and factors this into its own choice. The church or state is solving a static Ramsey-style problem, taking as given what the future church/state will do.

The experiment conducted for the baseline model is now rerun while incorporating the Ramsey problem solved by the church. To do this, simply select the constants on the opprobrium and cost functions to be unity so that $\kappa=v=1.0$; this conserves on parameter values. All else equal, the presence of church and state will result in less premarital sex in the model. The weight on the shame function is adjusted down slightly (from $\gamma=5.75$ to 5.59) to make sure that the extended model in its final steady state has the same fraction of girls engaging in premarital sex as the benchmark model; all other parameter values remain the same. Figure 8 shows the upshot. Over time, socialization by both the church and parents declines as premarital sex becomes safer. There is a sudden shift in attitudes in the latter quarter of the century. ${ }^{16}$ Out-of-wedlock births (measured in the model as the fraction of teenagers who became pregnant by age 19) start off at $7.7 \%$ of total births. The annual pregnancy rate for the United States in 1920 was $2.3 \%$. The annual rate must lie below the six-year rate, for which there are no data for 1920. The number of girls who become pregnant by age 19 rises from $7.7 \%$

16. Consider the following alternative extension that injects cultural dynamics into the analysis. Let $\boldsymbol{r}$ evolve according to

$$
\boldsymbol{r}=(1-v) \boldsymbol{s}+v \boldsymbol{r}_{-1},
$$

where the average level of socialization $s$ is given by

$$
\boldsymbol{s}=\sum_{y^{\prime}} S\left(\boldsymbol{e}, y^{\prime}\right) \bar{Y}\left(y^{\prime}\right)
$$

Here the opprobrium, $O(\boldsymbol{r})$, that parents feel when their child has an out-of-wedlock birth will adjust slowly over time to any new economic circumstances. Social attitudes will have a capital aspect to them. In this spirit, Fernández, Fogli, and Olivetti (2004) develop a model where men's preferences toward female labor-force participation change slowly over time in response to an increase in the fraction of working mothers in the population (promoting further participation). In their work there are no interested parties, such as churches, states or parents, trying to influence this evolution. The fact that the sexual revolution occurred so quickly may imply that $v$ must be small (in the context studied here). 

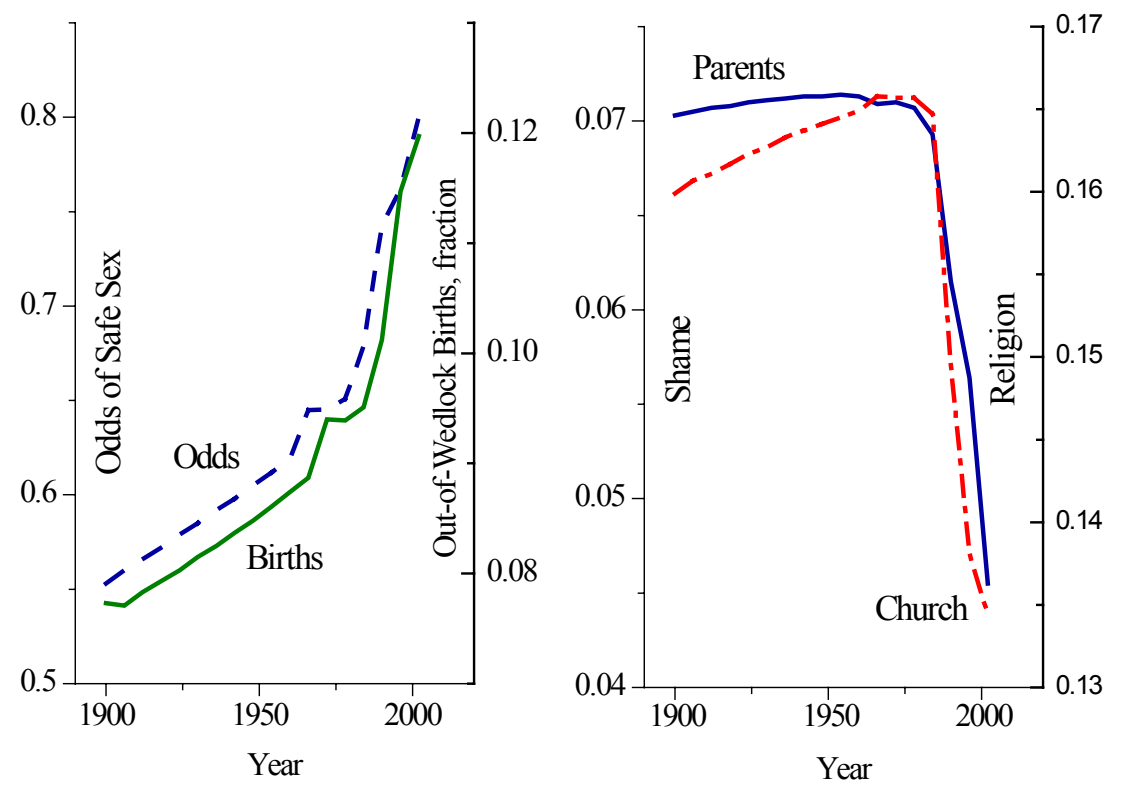

FIGURE 8. Socialization by church and parents.

in 1900 to $12 \%$ in 2002 . The presence of the church and state has significantly tamped down teenage pregnancies in the initial steady state compared with the benchmark model $(7.7 \%$ versus $11.7 \%)$. This occurs because there is much less premarital sex in the presence of church and state $(17 \%$ versus $26 \%)$.

\subsection{The Shift in Church Doctrine and the Decline in Proscription}

The historical record supports the idea of lower activity in modern times by the state and churches to reduce premarital sex. Most of the legal restrictions on illegitimate children started to be erased in the 1960s. The US Supreme Court, in Levy v. Louisiana, 391 U.S. 68 (1968), stated that the rights of a child to sue on a deceased parent's behalf may not be denied merely because a person is the illegitimate child of the deceased. The Supreme Court understood that such a limitation would violate the Equal Protection Clause of the Fourteenth Amendment. Moreover, the decision established that states were not permitted to classify people in a way that constitutes "invidious discrimination against a particular class". This idea of "invidious discrimination" was developed in a number of subsequent decisions that eliminated nearly all legal consequences of illegitimacy in the United States (although a few survive, mostly related to immigration status). Similar legal changes equalizing the legal rights of legitimate and illegitimate children spread quickly in Western European countries, including England (1969 and 1989), France (1972 and 2001), Germany (1969 and 1997), Italy (1975), and Spain (1981). In 2005, France went as far as removing the very concept of illegitimacy from its civil code. 
Churches, particularly mainline Protestant ones, also de-emphasized the existing strict provisions against premarital sex. In a famous example, the Episcopal Bishop of Newark, John Shelby Strong (a best-selling author of Christian books), called in 1987 for the recognition and blessing of nonmarital relations. In Europe, the movement was even stronger. For instance, the German Protestant Church published in 1971 a Memorandum on Questions of Sexual Ethics that implied that couples who intended to marry could decide for themselves whether premarital sex was acceptable; see Herzog (2007). The Catholic church still opposes virtually all forms of contraception following Pope John VI's proscription that "also to be excluded is any action which either before, at the moment of, or after sexual intercourse, is specifically intended to prevent procreation-whether as an end or as a means". The only method of contraception endorsed by the Catholic church is the standard days method, a calender day (rhythm) method specifying the days of the menstrual cycle during which it is safe to have sex. Its perfect-use efficacy is $95 \%$, while its efficacy in typical use drops to $88 \%$. Most teenagers either use condoms or the pill to prevent pregnancies. The Church is ambivalent about the use of condoms to prevent the transmission of AIDS. Pope Benedict XVI has said that, while on the one hand, the use of a condom does not deliver a "real or moral solution" to the AIDS problem, on the other hand, the use of a condom "with the intention of reducing the risk of infection, can be a first step in a movement towards a different way, a more human way, of living sexuality."

\section{Conclusions}

Engaging in a premarital conjugal relationship in yesteryear was a perilous activity for a young woman. The odds of becoming pregnant were high, given the primitive state of contraception. The economic consequences of an out-of-wedlock birth were dire for a young woman. Being born in or out of wedlock could be the difference between life or death for a child. Just like today, young adults would have weighed the cost and benefit of engaging in premarital sex. The cost would have been lower for women stuck at the bottom of the socioeconomic scale, so they would have been more inclined to participate. To tip the scale against premarital sex, parents socialized children to possess a set of sexual mores aimed at shaming sex. They did this in the face of external peer-group effects that may have encouraged young women to participate in premarital sexual activity. Parents at the lower end of the socioeconomic scale would have less incentive to engage in such practice.

The church and state also inveighed against premarital activity. Historically they were the main providers of charity for unwed mothers and out-of-wedlock children, a considerable expense. So, they had an economic incentive to stigmatize premarital sexual activity, in addition to caring about the well-being of their flock. Unlike parents, such institutions did have the ability to influence peer-group effects.

With the passage of time, contraception became more efficient and the costs of premarital sex consequently declined. This changed the cost and benefit calculation for young adults so that they would be more likely to participate in sexual activity. 
It also reduced the need for socialization by parents, or the church and state, which would also spur promiscuity. This is an example of culture following technological progress. An interesting question is why the cultural prohibitions on premarital sex were abandoned so quickly, while others, such as the dietary proscriptions associated with various religions, were not. Perhaps sexual attraction is such a primal urge that there is a huge individual incentive to abandon social norms, especially when they can be easily circumvented in private with improved contraception.

\section{Appendix: Data}

\section{A.1 Data Sources}

- Figure 1, right panel. The data on attitudes by women toward premarital sex are displayed in Figure 2 in Harding and Jencks (2003) and were kindly supplied by the authors. The numbers on the fraction of teenage girls who have experienced premarital sex by age 19 are taken from Greenwood and Guner (2010), which contains information about the source. Also, see the discussion in the Online Appendix, Section A.

- Figure 1, left panel. See Greenwood and Guner (2010) for detailed information on how the failure rates are constructed. The figure also shows out-of-wedlock births as a percentage of all unmarried females between the ages of 15 and 19. This number is called the illegitimacy ratio. The data on out-of-wedlock births for teenage girls are derived as follows. For 1960-2000 the data are taken from Greenwood and Guner (2010). For the 1972-2000 period it sums births to unmarried teenagers, all abortions to teenagers, and miscarriages (calculated as $20 \%$ of births plus $10 \%$ of abortions). For the 1960-1971 period it estimates the total number of pregnancies by simply assuming that the (abortions + miscarriages)/(out-of-wedlock births) ratio took the same value as it did in 1972 . For 1920, 1930, 1940, and 1950-1960 the series from Greenwood and Guner (2010) is extended using the same procedure. The data on out-of-wedlock births for 1940 and 1950-1960 are from Ventura, Mathews, and Hamilton (2001). For 1920 and 1930, using Bachu's (1999) estimates for 1930-1934, out-of-wedlock births are calculated as $14.5 \%$ of total births to teenagers. Total births to teenagers are from Heuser (1976).

- Figure 2. For the period 1580-1837 the data on out-of-wedlock births for all women are taken from Wrigley et al. (1997, p. 224). For the period 18422005 the source is Ermisch (2006, Figure 1). Wrigley and Schofield (1981, p. 230) provide data on the gross reproduction rate for 1541-1871. The data for 1876-2000 come from UK National Statistics.

- National Longitudinal Study of Adolescent Health (Add Health). This research uses data from Add Health. Persons interested in obtaining data files from Add Health should contact Add Health, Carolina Population Center, 123 W. Franklin 
Street, Chapel Hill, NC 27516-2524, USA (addhealth@unc.edu). Add Health is discussed further in the Online Appendix, Section B.

- Table 4, the cross-sectional relationship between a girl's education and the likelihood that she will have premarital sex. The data on premarital sex are calculated from the 2002 National Survey of Family Growth (NSGF) as the fraction of women between ages 20 and 44 who had premarital sex before age 19.

- Table 4, the amount of time that a mother spends with her child, as a function of the mother's educational background. The underlying time-use data are taken from the 2003 American Time Use Survey (ATUS). The figure plots the sum of educational and recreational childcare, normalized by 100 (total nonsleeping time per week). The sample includes all women between ages 20 and 44, who are not (early) retirees or students, had time diaries summing up to a complete day, and had at least one child under the age of 18 at home.

- Table 4, the correlation between a husband's and wife's education, conditional on the presence of an out-of-wedlock birth. This was computed from the data in the 2002 National Survey of Family Growth (NSFG).

- Figure 3 (and the cross-sectional facts on teenage sexual behavior and attitudes cited in the Introduction). Source: 2002 National Survey of Family Growth (NSFG). The sample contains all teenagers in the survey (15-19 years old).

- Table 6. National Longitudinal Study of Adolescent Health (Add Health) Restricted-Use Contractual data, Wave 1, 1994-1995. The sample contains all teenagers (15-19) who are not married and who did not experience forced sex.

\section{References}

Abma, Joyce C., Gladys M. Martinez, and Casey E. Copen (2010). "Teenagers in the United States: Sexual Activity, Contraceptive Use, and Childbearing," National Survey of Family Growth 2006-2008, Vital and Health Statistics Series 23, No. 30, National Center for Health Statistics.

Bachu, Amara (1999). "Trends in Premarital Childbearing: 1930-1994." Current Population Reports P23-197. US Census Bureau, Washington, DC.

Becker, Gary S. (1993). "The Economic Way of Looking at Behavior." Journal of Political Economy, 101, 385-409.

Becker, Gary S. and Casey B. Mulligan (1997). “The Endogenous Determination of Time Preference.” Quarterly Journal of Economics, 113, 729-758.

Beckert, Jens (2008). Inherited Wealth. Princeton University Press.

Bennett, Judith M. (2003). "Writing Fornication: Medieval Leyrwite and its Historians." Transactions of the Royal Historical Society, 6th Series, 13, 131-162.

Bisin, Alberto and Thierry Verdier (2001). "The Economics of Cultural Transmission and the Evolution of Preferences." Journal of Economic Theory, 97, 298-319.

Cameron, A. Colin and Pravin K. Trivedi (2005). Microeconometrics: Methods and Applications. Cambridge University Press.

Clark, Andrew E. and Youenn Loheac (2007). "It Wasn't Me, It Was Them! Social Influence in Risky Behavior by Adolescents." Journal of Health Economics, 26, 763-784.

Coleman, James S. (1990). Foundations of Social Theory. The Belknap Press of Harvard University Press. 
Doepke, Matthias and Fabrizio Zilibotti (2008). "Occupational Choice and the Spirit of Capitalism." Quarterly Journal of Economics, 123, 747-793.

Ermisch, John (2006). “An Economic History of Bastardy in England and Wales.”ISER Working Paper 2006-15, University of Essex.

Fernández, Raquel, Alessandra Fogli, and Claudia Olivetti (2004). "Mothers and Sons: Preference Transmission and Female Labor Force Dynamics." The Quarterly Journal of Economics, 119, 1249-1299.

Fernández, Raquel and Alessandra Fogli (2009). "Culture: An Empirical Investigation of Beliefs, Work and Fertility.” American Economic Journal: Macroeconomics, 1, 146-177.

Fuchs, Rachel (1992). Poor and Pregnant in Paris. Rutgers University Press.

Gale, David and Lloyd S. Shapley (1962). "College Admissions and Stability of Marriage." American Mathematical Monthly 69, 9-15.

Giuliano, Paola (2007). "Living Arrangements in Western Europe: Does Cultural Origin Matter?" Journal of the European Economic Association, 5, 927-952.

Godbeer, Richard (2002). Sexual Revolution in Early America. The Johns Hopkins University Press.

Greenwood, Jeremy and Nezih Guner (2010). "Social Change: The Sexual Revolution." International Economic Review, 51, 893-923.

Guiso, Luigi, Paola Sapienza, and Luigi Zingales (2006). "Does Culture Affect Economic Outcomes?" Journal of Economic Perspectives, 20(2), 23-48.

Guner, Nezih, Remzi Kaygusuz, and Gustavo Ventura. (2012). "Taxation, Aggregates and the Household." Review of Economic Studies, 79, 1113-1149.

Harding, David J. and Christopher Jencks (2003). "Changing Attitudes Toward Premarital Sex: Cohort, Period, and Aging Effects." Public Opinion Quarterly 67, 211-226.

Hauk, Esther and Maria Saez-Marti (2002). "On the Cultural Transmission of Corruption.” Journal of Economic Theory, 107, 311-335.

Hayden, Mary (1942-43). "Charity Children in Eighteenth-Century Dublin." Dublin Historical Record, 5, 92-107.

Herzog, Dagmar (2007). Sex after Fascism: Memory and Morality in Twentieth-Century Germany. Princeton University Press.

Heuser, Robert L. (1976). Fertility Tables for Birth Cohorts by Color: United States, 1917-1973. DHEW Publication No.(HRA) 76-1152.

Klepp, Susan (1994). "Lost, Hidden, Obstructed, and Repressed: Contraceptive and Abortive Technology in the Early Delaware Valley." In Early American Technology, edited by Judith A. McGaw. University of North Carolina Press, pp. 68-113.

Knowles, John A. (1999). "Parental Decisions and Equilibrium Inequality." Ph.D. Dissertation, Department of Economics, University of Rochester.

Sherwood, Joan M. (1989). Poverty in Eighteenth-Century Spain: The Women and Children of the Inclusa. University of Toronto Press.

Stone, Laurence (1977). The Family, Sex and Marriage in England 1500-1800. Weidenfeld and Nicolson.

Tabellini, Guido (2008). “The Scope of Cooperation: Values and Incentives.” Quarterly Journal of Economics, 123, 905-950.

Ventura, Stephanie J., T. J. Mathews, and Brady E. Hamilton (2001). "Births to Teenagers in the United States, 1940-2000." National Vital Statistics Report 49(10) National Center for Health Statistics.

Voigtländer, Nico and Hans-Joachim Voth (2013). "How the West 'Invented' Fertility Restriction." American Economic Review, 103(6), 2227-2264.

Witte, John, Jr. (2009). The Sins of the Fathers: The Law and Theology of Illegitimacy Reconsidered. Cambridge University Press.

Wrigley, Edward A., R. S. Davies, James. E. Oeppen, and Roger S. Schofield (1997). English Population History From Family Reconstruction 1580-1837. Cambridge University Press.

Wrigley, Edward A. and Roger S. Schofield (1981). The Population History of England 1541-1871: A Reconstruction. Harvard University Press. 


\section{Supporting Information}

Additional Supporting Information may be found in the online version of this article at the publisher's website:

The Online Appendix has three sections:

- Online Appendix, Section A; Historical Discussion;

- Online Appendix, Section B: Evidence on Shame and Peer-Group Effects in the United States;

- Online Appendix, Section C: Theory. 


\section{Online Appendix \\ "From Shame to Game in One Hundred Years: An Economic Model of the Rise in Premarital Sex and Its De-Stigmatization" \\ by}

Jesús Fernández-Villaverde, Jeremy Greenwood, and Nezih Guner

\section{Historical Discussion}

The experience for other Western European countries is similar to that discussed for England and the U.S. Therborn (2004, p. 149) reports that the percentage of children born out of wedlock among live births around 1896-1900 was 6\% in Australia, 8\% in Belgium, $9 \%$ in Germany, $6 \%$ in Italy, $4 \%$ in New Zealand, $3 \%$ in the Netherlands, $2 \%$ in Ontario (Canada), $5 \%$ in Spain, and 5\% in Switzerland. Furthermore, prenuptial conception (i.e., births happening less than 9 months after the wedding) was relatively low. The notion of prenuptial pregnancies is discussed below.

The starting point of the historical analysis is that with primitive contraceptive technology, pregnancies are a good estimate of illicit sexual behavior. One could also look at the out-of-wedlock births as a percentage of all unmarried women (or the illegitimacy rate). Unfortunately, it is difficult to obtain an estimate of the number of unmarried women in yesteryear. Laslett (1980, Fig 1.1) plots this rate for the period 1855 to 1975 . It varies between 1.0 to $2.0 \%$, which is low. This measure is for all women ages 15-44; it should be lower for teenage girls.

Another measure of illegitimacy is the prenuptial pregnancy ratio. This gives the percentage of first births that are conceived before marriage. Now, as Wrigley et al. (1997, p. 422) emphasize, "(b)irths conceived well before marriage were probably more closely akin to illegitimate births than to those prenuptial conceptions which took place immediately before marriage. The latter class of prenuptially conceived births were arguably the product of behavior licensed by formal betrothal ..." Between 1538-1837, 74\% of first births occurred 9 months or more after the marriage date; see Wrigley et al. (1997, Table 7.27). The remaining $26 \%$ were prenuptial pregnancies. Close to one third of these occurred within 2 months of the marriage. Indeed, only $6 \%$ of first births were delivered 2 months after a marriage. Does the presence of prenuptial births indicate widespread promiscuity? First, the number is small. Second, "(o)n one interpretation of the marriage practices of traditional English society there was a form of matrimony quite widespread at the time, though probably varying from place to place, where each partner was at liberty to go to bed with the other directly a match had been definitely decided upon, although the church wedding was still in the future. Under 
such circumstances both the man and the woman can be assumed to have had the intention of accepting the risk of pregnancy during the interval between the decision to marry and nuptial celebration in the church. Pre-nuptial pregnancy arising in this way ... must be held to be entirely distinct from bastardy" Laslett (1977, p. 129). In fact in early times (14th century) a betrothal that was followed by intercourse was viewed by the Church as a legally binding marriage contract [Stone (1977, p. 604)]. Chief Justice Holt ruled in 1704 that "if a contract be per verba de praesenti, it amounts to an actual marriage which the very parties themselves cannot dissolve by release or mutual agreements, for it is as much a marriage in the sight of God as if it had been in facie ecclesiae."

So, the concept of prenuptial pregnancy is problematic for the analysis here. The analysis stresses the shame, stigma and the reduced economic opportunities from having an out-ofwedlock birth. Any prenuptial conception that ended up in a marriage with the father of the child was unlikely to generate much lower income and the shame of prenuptial conceptions was clearly an order of magnitude smaller. The concept of illegitimacy is much closer to the notion of illicit sexual behavior modelled here.

The extent of prenuptial sex in early America is subject to debate. Smith (1980) reports that prior to 1750 less than $10 \%$ of first births would have been conceived within 6 months after a formal marriage. ${ }^{17}$ The number jumps to $16 \%$ during the second half of the eighteenth century and then declines. He notes that outside of the 20th century "the fundamental quantitative data are scattered and of uncertain quality (p. 362)." Wells (1980, p. 353) writes that his research on Quaker brides "is at odds" with the above findings. He finds that in the second half of the eighteenth century only $3.7 \%$ of brides delivered babies within seven months of marriage. He notes that "to the extent that colonists considered nuptials to begin with the engagement rather than the wedding, counting the number of first births within seven months of the wedding as prenuptially conceived may do injustice to the colonial standards of morality" (p. 351). This is especially important because early America was quite "unchurched." Smith (1980, p. 364) notes that "(t)hrough its history America has lacked either religious uniformity and an active religious bureaucracy or a well organized and inquisitive state." As the U.S. became a more "structured" society in the first half of the nineteenth century, prenuptial conceptions fell significantly. The role of religion in preventing premarital sex will be stressed in the current analysis. Additionally, Smith (1980, Table 17.5) shows very low illegitimacy ratios and rates for white females in nineteenth century America (on the order of 1 to $2 \%$ and 0.2 to $0.4 \%$, respectively); in fact, they are much lower than the rates he reports for England and Wales for the same time period.

\footnotetext{
${ }^{17}$ This research is based on his earlier 1975 work with M.S. Hindus "Premarital Pregnancy in America, 1640-1971: An Overview and Interpretation," in the Journal of Interdisciplinary History.
} 
The quantitative analysis here focuses on twentieth century America, for which all researchers agree the data are much better. The data on premarital sex for the first part of the century are from the famous Kinsey et al. (1953) study; see the first three points in Figure 1. The samples used are relatively large. They pertain to premarital sex for teenage women. Smith (1980, Table 17.3) relays, on the basis of data from the U.S. Bureau of the Census, that only $7.4 \%$ of first births in 1900-1909 for all women were within 8 months of the marriage. This seems in line with the $2.3 \%$ illegitimacy rate for unmarried teenage girls in 1900 plotted in Figure 2. Smith's (1980, Table 17.4) own small sample gives a number for this time somewhere between 15 and $23 \%$, which suggests it is not representative. In fact, he acknowledges that his series is "heavily biased toward rural New England population samples" (p. 370).

According to Shorter (1975, p. 80) "(b)efore 1800 it was unlikely that the typical young woman would have had coitus with her partner-certainly not before an engagement had been sealed and probably not as a fiancée, either." What happened in the 1800s is unclear: some researchers believe that it rose from a small to modest level and then fell [such as Smith (1980) reports for the U.S.]. This is very different from modern times, where the vast majority of all women (over 90\%) have had premarital sex and the typical woman would have had more than one partner before marriage. The average is now likely to be 3 to 4 partners. This begs the question: Why was illicit sex so limited in the past? The idea here is that premarital sex was shamed and stigmatized by society in order to dissuade it.

The shame and stigma attached to premarital sex, and other forms of illicit sex, is reflected by the language used to describe such acts. Words such as debauched, lascivious, lewd, loose, incontinent, vain and wanton were used to reflect a lack of self control; others such as base, defiling, polluting, unclean, and vile described the desecration of the body associated with illicit sex; yet others such as adultery, disorderly, indolation, misdirection, rebellion, uncivil, unlawful conjured up the notion of civil or religious disobedience and affected even those in situations of social prestige and power. So, for example, the son and namesake of the renowned minister John Cotton was excommunicated in 1664 by the First Church of Boston "for lascivious unclean practices with three women."

Policies directed at generating stigma, rather than explicit punishment, were widespread. For instance, in colonial Virginia, women who engaged in premarital sex were required to offer a public apology, dressed in a white sheet and carrying a white wand, in front of the congregated parish; see Brown (1996). Finally, there were more informal instruments in the form of some socially sanctioned activities such as supervised courtship rituals or the spread of the charivari as a ritual prosecution; see Muir (2005). A particularly interesting strategy was the New England practice of "bundling." A courting couple were allowed to lie together but 
separated by a bundling board with, often, the woman's legs bound together by a bundling stocking; see Fischer (1989). This institution allowed intimacy for the young couple without sexual contact.

\section{Evidence on Shame and Peer-Group Effects in the U.S.}

\subsection{Sample}

The statistical analysis includes all girls between the ages of 15 and 19 in Wave I who have: (i) responded in both Wave I and Wave II, so that their transitions can be calculated; and (ii) responded consistently. There are two types of inconsistencies: (a) those who say they have had sex in Wave I, but report they have never had sex in Wave II; (b) those who say they have never had sex in Wave I, report they have had sex in Wave II, but the date given for their sexual intercourse is before Wave I. All these observations are dropped. Additionally, all girls are dropped who: (i) have been married (a small number); (ii) have had involuntary sex; and (iii) were in schools with less than 5 respondents. For the "peers" of a respondent all girls between the ages 15 and 19 who are in the same school are considered. The sample is restricted to girls in schools where at least 5 girls responded. The sample consists of 2,354 teenage girls who have never had sex in Wave I. Among them about $20 \%$ initiated sex between Wave I and Wave II. Table A.I shows sample statistics for the variables used in the basic regression. 


\begin{tabular}{lcc}
\hline \hline & Mean & Stan. Dev. \\
Initiate Sex between Wave I and Wave II & 0.184 & 0.388 \\
Peer Group (students from respondent's school & 0.364 & 0.129 \\
who initiated sex by Wave I) & \\
Shame & -0.314 & 0.764 \\
Parental Income (\$) & 53,913 & 63,968 \\
Grades (average of grades in math, English, & 1.925 & 0.716 \\
science and social sciences, with 1 being grade A and 4 being grade D) & \\
Romantic Relations (fraction of respondents who have a romantic & 0.567 & 0.496 \\
relation in Wave II) & & \\
Physical Development (fraction of respondents who feel they look & 0.360 & 0.480 \\
older than average) & & \\
Age & 15.83 & 0.894 \\
Percentage White & 0.785 & 0.411 \\
Percentage Black & 0.111 & 0.314 \\
\hline \hline
\end{tabular}

\subsection{Factor Analysis}

In the data set there are many variables on shame, religion, etc. Using all of these variables simultaneously induces a problem of multicollinearity. In the analysis a single variable, "shame," is constructed using factor analysis from the answers to a set of 11 questions. Factor analysis is used to identify or confirm the latent factor structure for a group of measured variables; see Harman (1967). Latent factors are unobserved variables that can not be directly measured but are assumed to affect observed outcomes. In the current application, the latent factor is the "shame" that affects the answers that adolescent girls give to certain questions in Add Health.

Consider $n$ variables with $N$ observations (respondents) each, and suppose each of these variables is affected by $m$ different latent factors. Then, a factor analysis model is given by

$$
\begin{aligned}
x_{1}-\mu_{1}= & l_{11} f_{1}+l_{12} f_{2}+\ldots+l_{1 m} f_{m}+\varepsilon_{1} \\
x_{2}-\mu_{2}= & l_{21} f_{1}+l_{22} f_{2}+\ldots+l_{2 m} f_{m}+\varepsilon_{2} \\
& \vdots \\
x_{n}-\mu_{n}= & l_{n 1} f_{1}+l_{n 2} f_{2}+\ldots+l_{n m} f_{m}+\varepsilon_{n},
\end{aligned}
$$


or in matrix notation by

$$
\mathbf{X}=\mathbf{L F}+\varepsilon
$$

where $\mathbf{X}$ is $n \times N, \mathbf{L}$ is $n \times m, \mathbf{F}$ is $m \times N$, and $\varepsilon$ is an $n \times N$ matrix. Here $x_{i k}$ is the $i$-th observed variable for respondent $k, \mu_{i}$ is its mean across the $N$ observations, $f_{j k}$ is the $j$-th common random latent factor for respondent $k$ and $\varepsilon_{i k}$ is the unobserved error term for the $i$-th variable for respondent $k$. The basic assumptions are that the unobservable random vectors $\mathbf{F}$ and $\varepsilon$ are independent with $E(\mathbf{F})=0, \operatorname{Cov}(\mathbf{F})=\mathbf{I}, E(\varepsilon)=\mathbf{0}, \operatorname{Cov}(\varepsilon)=\mathbf{\Psi}$, where $\boldsymbol{\Psi}$ is a diagonal matrix. The $l_{i j}$ 's are called factor loadings.

Note that since

$$
\mathbf{X} \mathbf{X}^{\prime}=\mathbf{L} \mathbf{F F} \mathbf{L}^{\prime}+\mathbf{L F} \varepsilon^{\prime}+\varepsilon \mathbf{F}^{\prime} \mathbf{L}^{\prime}+\varepsilon \varepsilon^{\prime}
$$

the correlation matrix for the data can be written as

$$
\mathbf{R}_{\mathbf{X X}}=\mathbf{L R}_{\mathbf{F F}} \mathbf{L}^{\prime}+\mathbf{L R}_{F \varepsilon}+\mathbf{R}_{\varepsilon F} \mathbf{L}^{\prime}+\mathbf{R}_{\varepsilon \varepsilon}
$$

where the operator $\mathbf{R}$ indicates a correlation matrix. Under the assumptions on $\mathbf{F}$ and $\boldsymbol{\varepsilon}$ (i.e., $\mathbf{R}_{F \varepsilon}=\mathbf{R}_{\varepsilon F}=0$ and $\mathbf{R}_{\mathbf{F F}}=\mathbf{I}$ ), this expression becomes

$$
\mathbf{R}_{\mathbf{X X}}=\mathbf{L L}^{\prime}+\mathbf{R}_{\varepsilon \varepsilon}
$$

The basic idea of factor analysis is to find the $\mathbf{L}$ that minimizes $\mathbf{R}_{\varepsilon \varepsilon}$. Note that $\mathbf{R}_{\mathbf{X x}}$ does not depend on $\mathbf{F}$. Once $\mathbf{L}$ is found, the factor matrix $\mathbf{F}$ can be recovered. In particular, consider the following linear regression of any factor $j$ on the $n$ observed variables:

$$
f_{j}=\beta_{j 1} x_{1}+\beta_{j 2} x_{2}+\ldots+\beta_{j n} x_{n}, j=1, . ., m
$$

If the $\beta$ values are known, then a factor for each respondent can be calculated as

$$
f_{j, i}=\beta_{j 1} x_{1, i}+\beta_{j 2} x_{2, i}+\ldots+\beta_{j n} x_{n, i}, k=1, . ., m, \text { and } i=1, \ldots, N
$$

It can be shown that, Harman (1967, Chapter 16),

$$
\boldsymbol{\beta}_{j}=\mathbf{R}_{\mathbf{X X}}^{-1} \mathbf{L}_{j}^{\prime}
$$

where $\mathbf{L}_{j}^{\prime}=\left[l_{1 j}, l_{2 j}, \cdots, l_{n j}\right]^{\prime}$ is an $n \times 1$ vector of factor loadings.

In the current analysis the $x_{i}$ 's represent the answers to the 11 survey questions shown in Table A.2. There are 3,309 observations. A single "shame" factor is constructed so that $\mathbf{L}$ is 
an $11 \times 1$ vector and $\mathbf{F}$ is a $1 \times 3,309$ vector. This single shame factor explains about $50 \%$ of the variation in these 11 variables. Table A.2 shows the factor loadings (the $l_{i}$ values for $i=1, \cdots, 11)$ for the analysis. As the relative sizes of the factor loadings show, the shame factor has a large influence on a respondent's guilt from premarital sex and on how she thinks her mother will feel about her engaging in the act.

TABle A.2: FACtor LoAdings

How would your mother feel about...

H1PA1. your having sex at this time in your life?

0.665

H1PA2. your having sexual intercourse with someone who was special

If you had sexual intercourse...

H1MO2. your partner would lose respect for you

H1MO3. afterward, you would feel guilty

H1MO4. it would upset your mother

If you got pregnant....

H1M09. it would be embarrassing for your family.

0.468

H1MO10. it would be embarrassing for you

H1RE3. In the past 12 months, how often did you attend religious services? 0.478

H1RE4. How important is religion to you?

H1RE6. How often do you pray?

0.366

H1RE7. In the past 12 months, how often did you attend youth

0.400

activities in churches/synagogues/etc.?

\subsubsection{Correlated Effects}

A potential problem in identifying peer-group effects is the presence of correlated effects. Peer groups may not be formed randomly. Perhaps a teenager associates with her peers because they have similar unobserved characteristics. If you are interested in having sexual relationships, then you may choose to associate with others who share this predisposition; see Greenwood and Guner (2010) for a model of this. In the analysis below peer groups are based on a teenager's school, assuming that the school is exogenous to the individual and parental characteristics of the respondent. Since school choice by parents might be partly endogenous, some further controls are considered. First, in Wave I, Add Heath asks parents 
if they chose a particular neighborhood for school quality. This can be controlled for in the analysis. Second, it is possible to differentiate between those teenagers who have moved to a neighborhood recently (within a year) and those who have been living there longer. Since correlated effects are likely to be different for these two groups, one can also control for whether the respondent is a recent resident. Teenagers within a particular school might also behave in a similar way, since they face the same institutional constraints. To control for this, further regressors can be added to capture school characteristics.

In Table A.3, additional controls are added to correct for correlated effects. Whether parents chose a particular neighborhood for school quality or whether the respondent moved into the current residence less than one year ago enter these regressions significantly. ${ }^{18}$ The magnitudes of peer-group effects and shame are not affected in a material way, although the peer-group effect is now only significant at the $10 \%$ level. Some additional controls are also considered, viz., school type (public, private and religious), school location (urban, suburban and rural), school size, class size, the fraction of teachers with a master's or Ph.D. degree, the proportion of teachers who have been working more than 5 years at the school, the proportion of parents involved in parents' organizations at the school, and the proportion of white students in the school. None of these variables turn out to be significant and they do not affect the basic findings. 19

\begin{tabular}{lll} 
TABle A.3: Controlling For & Correlated Effects \\
\hline \hline & I & II \\
School Average & $1.699^{*}$ & $1.716^{*}$ \\
Shame & $0.616^{* * *}$ & $0.606^{* * *}$ \\
Parental Income & $-0.008^{* * *}$ & $-0.008^{* *}$ \\
Romantic Relationship & $1.648^{* * *}$ & $1.649^{* * *}$ \\
Grades & $0.356^{* *}$ & $0.353^{* *}$ \\
Physical Development & $0.600^{* * *}$ & $0.581^{* * *}$ \\
Parental Choice & 0.046 & \\
Recent Movers & & -0.034 \\
Control For Race & Yes & Yes \\
Control for Age & Yes & Yes \\
Number of Obs. & 1,119 & 1,142 \\
\hline \hline
\end{tabular}

\footnotetext{
${ }^{18}$ The idea to differentiate between recent and not-so-recent movers was initially suggested by Gaviria and Raphael (2001).

${ }^{19}$ Average values for some of the control variables among the respondents' peers were also added to the regressions in Table I (in the main body of the paper) in order to control for what the literature calls exogenous (or contextual) effects. Including these exogenous variables in the regressions did not change the basic findings.
} 


\subsection{Instrumental Variable Analysis}

Manski (2000) and, in more detail, Brock and Durlauf (2001a,b) demonstrate that the reflection problem is less severe in a discrete choice model with social interactions because identification is derived from the nonlinear structure of the problem. Nevertheless, it is still useful to exploit the panel structure of the data, as was done in Section 3, to minimize this (and other) problems of small samples.

The existing empirical literature on teenage sexual (or other) behavior usually relies on cross-sectional data and tries to overcome the reflection problem by using instrumental variables (IV). A common strategy is to define peers as students who are in the same grade as the individual under study and use the peers' characteristics as instrumental variables for their sexual behavior. ${ }^{20}$ Since the peer group is defined at the grade level, school fixed effects are added to these regressions to control for correlated effects. ${ }^{21}$ Some IV estimates of peer-group effects are reported below using Wave I of Add Health. Consistent with the previous literature a significant peer-group effect is found when shame is ignored as a right-hand side variable. When shame is added as an explanatory variable, peer-group effects become insignificant.

Table A.4 shows the results from OLS and IV estimation of a linear probability model

$$
\operatorname{Pr}\left(y=1 \mid \mathbf{x}, \bar{y}_{-i}\right)=\alpha+\beta \mathbf{x}+\gamma \bar{y}_{-i}
$$

where the average characteristics of peers, $\mathbf{x}_{-i}$, are used as instruments for $\bar{y}_{-i}$. Here the dependent variable is whether or not the girl had sexual intercourse during Wave I. The peers are defined as students who are in the same grade in the same school. Regressions include school fixed effects. The table also reports the first stage $F$-test for the joint significance of the instruments and Sargan's overidentification test. The null hypothesis of weak instruments (the first stage $F$-test) is rejected. The instruments jointly pass the exogeneity requirement (the Sargan test). The size of peer-group effects in column II implies that a 1-percentagepoint increase in the share of girls who had premarital sex in the same grade as the respondent increases the probability of having premarital sex by 0.38 percentage points.

\footnotetext{
${ }^{20}$ See, for example, Fletcher (2012) or Richards (2010) for recent applications.

${ }^{21}$ Equation (1), in the main body of the paper, could be estimated with peers defined at the grade, instead of school, level. Since the analysis focuses on the initiation of premarital sex between Wave I and Wave II, the sample size is too small here to conduct the analysis at the grade level.
} 
Table A.4: Peer-Group Effects and Shame, IV Estimates

\begin{tabular}{lllll}
\hline \hline & I (OLS) & II (IV) & III (OLS) & IV (IV) \\
Grade Average & -0.077 & $0.381^{* *}$ & -0.133 & 0.237 \\
Shame & & & $0.189^{* * *}$ & $0.187^{* * *}$ \\
Parental Income & -0.0002 & -0.0002 & -0.0001 & -0.0001 \\
Romantic Relationship & $0.355^{* * *}$ & $0.354^{* * *}$ & $0.288^{* * *}$ & $0.288^{* * *}$ \\
Grades & $0.109^{* * *}$ & $0.115^{* *}$ & $0.066^{* * *}$ & $0.072^{* *}$ \\
Physical Development & $0.075^{* * *}$ & $0.079^{* * *}$ & $0.066^{* * *}$ & $0.071^{* * *}$ \\
Control for Race & Yes & Yes & Yes & Yes \\
Control for Age & Yes & Yes & Yes & Yes \\
School Fixed Effects & Yes & Yes & Yes & Yes \\
First Stage F-test & & 297.928 & & 271.533 \\
& & $(\mathrm{p}=0.000)$ & & $(\mathrm{p}=0.000)$ \\
Sargan Overidentification Test & & 6.943 & & 7.583 \\
& & $(\mathrm{p}=0.225)$ & & $(\mathrm{p}=0.270)$ \\
Number of Obs. & 2,718 & 2,718 & 2,345 & 2,345 \\
\hline \hline
\end{tabular}

\section{Theory}

\subsection{Positive Assortative Matching}

Recall that the expected lifetime utility in marriage accruing from consumption and other factors is a public good, enjoyed in equal fashion by husband and wife. Suppose that there is perfect assortative mating based on what each party will contribute to this expected lifetime utility, as measured by $\mathbf{L}(y, \widetilde{y}, I)$. The lifetime utility realized for a type- $\left(y_{f}, y_{m}, I\right)$ household will be

$$
\mathbf{L}(y, \widetilde{y}, I) \equiv \sum_{y^{\prime}} M^{*}\left(y, \widetilde{y}, I, y^{\prime}\right) Y\left(y^{\prime} \mid y\right),
$$

where $M^{*}\left(y, \widetilde{y}, I, y^{\prime}\right)$ is defined by $\mathrm{P}(1)$. There will be $2 n^{2}$ possible pairings for $\mathbf{L}$. Let $F$ represent the joint distribution for females over $\left(y_{j}, I\right)$. Then, the number of unmarried females of type $\left(y_{j}, I\right)$ at the beginning of adult life is given by $F\left(y_{j}, I\right)$. Similarly, \# $\left(\widetilde{y}_{k}\right)$ denotes the number of type- $\widetilde{y}_{k}$ males. Here assume for simplicity that $F\left(y_{k}, 0\right)+F\left(y_{k}, 1\right)=$ $\#\left(\widetilde{y}_{k}\right)$; i.e., the number of females and males of type- $k$ productivity is the same.

To characterize the implied matching process simply make a list of lifetime utilities from pairings, starting from the top and going down to the bottom. The best females will be matched with the best males. Now, suppose that there are more of these males than females. Then, some of the males will have to match with the next best females on the list. The 
matching process continues down this list in this fashion. At each stage the remaining best males are matched with the remaining best females. If there is an excess supply of one of the sexes, the overflow of this sex must find a match on the next line(s) of the list.

Now, suppose that the $l$-th position on the list is represented by a match of type $\left(y_{j}, \widetilde{y}_{k}, I\right)$. Some type- $\widetilde{y}_{k}$ males may have already been allocated to females who are higher on the list, i.e., to women that have a better combination of $y$ and $I$. Let $R_{m}^{l}\left(\widetilde{y}_{k}\right)$ be the amount of remaining type- $\widetilde{y}_{k}$ males who can be allocated at the $l$-th position on the list. Similarly, let $R_{f}^{l}\left(y_{j}, I\right)$ be the number of available type- $\left(y_{j}, I\right)$ females. The number of matches is given by $\min \left\{R_{m}^{l}\left(\widetilde{y}_{k}\right), R_{f}^{l}\left(y_{j}, I\right)\right\}$. Thus, the odds of a match (which may be zero) are

$$
\operatorname{Pr}\left(\widetilde{y}_{k} \mid y_{j}, I\right)=\min \left\{R_{m}^{l}\left(\widetilde{y}_{k}\right), R_{f}^{l}\left(y_{j}, I\right)\right\} / F\left(y_{j}, I\right)
$$

The matching process is summarized by

$\begin{array}{cccc}\text { Ranking } & \text { Lifetime Utility } & \text { Odds } \\ 1 & \mathbf{L}\left(y_{n}, \widetilde{y}_{n}, 0\right) & \operatorname{Pr}\left(\widetilde{y}_{n} \mid y_{n}, I=0\right)=1 & \\ & \vdots & \vdots & \\ l & \mathbf{L}\left(y_{j}, \widetilde{y}_{k}, I\right) & \operatorname{Pr}\left(\widetilde{y}_{k} \mid y_{j}, I\right)=\min \left\{R_{m}^{l}\left(\widetilde{y}_{k}\right), R_{f}^{l}\left(y_{j}, I\right)\right\} / F\left(y_{j}, I\right) \\ \quad \vdots & \vdots & \vdots \\ 2 n^{2} & \mathbf{L}\left(y_{1}, \widetilde{y}_{1}, 1\right) & \operatorname{Pr}\left(\widetilde{y}_{1} \mid y_{1}, I=1\right)=1,\end{array}$

where $R_{m}^{l+1}\left(\widetilde{y}_{k}\right)=R_{m}^{l}\left(\widetilde{y}_{k}\right)-\min \left\{R_{m}^{l}\left(\widetilde{y}_{k}\right), R_{f}^{l}\left(y_{j}, I\right)\right\}$, with $R_{m}^{1}\left(\widetilde{y}_{k}\right)=\#\left(\widetilde{y}_{k}\right)$, and $R_{f}^{l+1}\left(y_{j}, I\right)=$ $R_{f}^{l}\left(y_{j}\right)-\min \left\{R_{m}^{l}\left(\widetilde{y}_{k}\right), R_{f}^{l}\left(y_{j}, I\right)\right\}$, with $R_{f}^{1}\left(y_{j}, I\right)=F\left(y_{j}, I\right)$.

It is immediate that $Y^{m}\left(\widetilde{y}_{j} \mid y, I\right)=\operatorname{Pr}\left(\widetilde{y}=\widetilde{y}_{j} \mid y, I\right)$. Now, the distribution function $Y^{m}(\widetilde{y} \mid y, 0)$ will stochastically dominate the one represented by $Y^{m}(\widetilde{y} \mid y, 1)$, because having an out-ofwedlock birth will not increase the chances of a female drawing a male with an income greater than some specified level.

Any degree of assortative matching in the economy can be obtained by assuming that some fraction $\mu$ of each type mates in the above fashion, while the remaining fraction, $1-\mu$, matches randomly. With random matching $\operatorname{Pr}(\widetilde{y} \mid y, I)=\#(\widetilde{y})$, so that $Y^{m}\left(\widetilde{y}_{j} \mid y, I\right)=\#\left(\widetilde{y}_{j}\right)$.

The matching process follows the Gale and Shapley (1962) algorithm; see Del Boca and Flinn (2006) for a recent marriage application. The cue for randomness in matching comes from Fernández and Rogerson (2001). Since all consumption for the couple is a public good, there are no opportunities for transfers between the husband and wife here. Also, there are no complementarities between the husband's and wife's types in the production of household 
income. If these assumptions were relaxed, then a matching process along the lines of Becker (1981) could be used; see Chiappori, Iyigun and Weiss (2009) or Choo and Siow (2006) for recent work using this approach.

An out-of-wedlock birth makes it more likely that a woman will never marry. In the modern era, a teenager with an out-of-wedlock birth had a $16 \%$ chance of never marrying by ages $40-44$, versus $9 \%$ for a teenager without an out-of-wedlock birth [based on data from the 2002 National Survey of Family Growth (NSFG)]. The Gale-Shapley (1962) algorithm could be modified to allow for this. Imagine making a deduction from household utility for an out-of-wedlock birth, say $\kappa$. Then, some males and females may find it better to remain single than to accept the best match they can attain in the marriage market. Undertaking such an extension would involve computing the value of single life for men and women. ${ }^{22}$ Additionally, women who have an out-of-wedlock birth, while teenagers, tend to have more children. In particular, they have 2.8 children on average versus 2.1 for those women who did not (for married women, ages 40-44). Extending the framework to allow for endogenous fertility brings some interesting questions to the foreground. Would some girls choose to have an out-of-wedlock birth? Should they take the survival odds of the child into account when considering this, an important factor historically? The calibration strategy adopted in Section 8 penalizes an out-of-wedlock birth in a fairly flexible way. Hopefully, it picks up some aspects of these unmodelled costs.

\subsection{Proof (Balanced Growth)}

Proof. It is easy to see that both $U\left(y^{\prime}, \widetilde{y}^{\prime}, 0\right)-U\left(y^{\prime}, \widetilde{y}^{\prime}, 1\right)$ and $D\left(y^{\prime}, 0\right)-D\left(y^{\prime}, 1\right)$ are not functions of $\chi$, when given the functional forms (10) and (11). Given this, the result follows almost immediately from the first-order condition (6), as can be deduced from a guess-andverify procedure. Suppose that $s, s^{\prime}, s^{\prime \prime}, \cdots$ are unaffected by $\chi$. Then, there is no impact on the matching probabilities, $Y^{m}\left(\widetilde{y}^{\prime} \mid y^{\prime}, I^{\prime}\right)$ 's, because a shift in $\chi$ does not change the ranking or mass of each type of female. The difference in expected lifetime utilities, $A^{\prime}\left(y^{\prime}, 0\right)-A^{\prime}\left(y^{\prime}, 1\right)$, is not affected by $\chi$. This implies that $-E_{1}\left(s, \mathbf{e}, y^{\prime}\right)$ will remain constant from $(3)$ and $(7)$. Condition (6) still holds.

\section{References}

[1] Aiyagari, S. Rao, Jeremy Greenwood, and Nezih Guner (2000). "On the State of the Union." Journal of Political Economy, 108(2), 213-244.

\footnotetext{
${ }^{22}$ An example of such an analysis is contained in Aiyagari, Greenwood and Guner (2000).
} 
[2] Becker, Gary S. (1981). A Treatise on the Family. Harvard University Press.

[3] Brock, William A. and Steven N. Durlauf (2001,a). "Discrete Choice with Social Interactions." Review of Economic Studies 68(2), 235-60.

[4] Brock, William A. and Steven N. Durlauf (2001,b). "Interactions-based Models." In Handbook of Econometrics, 5, edited by James J. Heckman and Edward E. Leamer. Elsevier, pp. 3297-3380.

[5] Brown, Kathleen M. (1996). Good Wives, Nasty Wenches, and Anxious Patriarchs. Gender, Race, and Power in Colonial Virginia. University of North Carolina Press.

[6] Chiappori, Pierre-Andre, Murat Iyigun, and Yoram Weiss (2009). "Investment in Schooling and the Marriage Market." American Economic Review, 99(5), 1689-1713.

[7] Choo, Eugene and Aloysius Siow (2006). "Who Marries Whom and Why." Journal of Political Economy, 114(1), 175-201.

[8] Del Boca, Daniela and Christopher J. Flinn (2006). "Household Time Allocation and Modes of Behavior: A Theory of Sorts." Working Paper, Department of Economics, New York University.

[9] Fernández, Raquel and Richard Rogerson (2001). "Sorting and Long-Run Inequality." The Quarterly Journal of Economics, 116(4), 1305-1341.

[10] Fischer, David H. (1989) Albion's Seed: Four British Folkways in America. Oxford University Press.

[11] Gaviria, Alejandro and Steven Raphael (2001). "School-based Peer Effects and Juvenile Behavior." Review of Economics and Statistics, 83(2), 257-268.

[12] Harman, Harry H. (1967). Modern Factor Analysis. The University of Chicago Press.

[13] Kinsey, Alfred C., Wardell B. Pomeroy, Clyde E. Martin, and Paul H. Gebhard (1953). Sexual Behavior in the Human Female. W.B. Saunders Company.

[14] Laslett, Peter (1977). Family Life and Illicit Love in Earlier Generations. Cambridge University Press.

[15] Laslett, Peter (1980). "Introduction: Comparing Illegitimacy over Time and between Cultures." In Bastardy and its Comparative History, edited by Peter Laslett, Karla Oosterveen, and Richard M. Smith. Edward Arnold, pp 1-64. 
[16] Manski, Charles F. (2000). "Economic Analysis of Social Interactions." Journal of Economic Perspectives 14(3), 115-136.

[17] Muir, Edward (2005). Ritual in Early Modern Europe. Cambridge University Press.

[18] Richards, Seth (2010). "Peer Effects in Sexual Initiation: Separating Social Norms and Partner Supply." Mimeo, University of Pennsylvania.

[19] Shorter, Edward (1975). The Making of the Modern Family. Basic Books, Inc., Publishers.

[20] Smith, Daniel Scott (1980). "The Long Cycle in American Illegitimacy and Prenuptial Pregnancy." In Bastardy and its Comparative History, edited by Peter Laslett, Karla Oosterveen, and Richard M. Smith. Edward Arnold, pp. 362-378.

[21] Therborn, Göran. (2004). Between Sex and Power: Family in the World 1900-2000. Routledge.

[22] Wells, Robert V. (1980). "Illegitimacy and Bridal Pregnancy in Colonial America." In Bastardy and its Comparative History, edited by Peter Laslett, Karla Oosterveen, and Richard M. Smith. Edward Arnold, pp. 349-361. 